\title{
How land-use intensity affects sexual and parthenogenetic oribatid mites in temperate forests and grasslands in Germany
}

\author{
Katja Wehner $^{1}$ (D) Romina Schuster ${ }^{2} \cdot$ Nadja K. Simons ${ }^{1} \cdot$ Roy A. Norton ${ }^{3}$. \\ Nico Blüthgen ${ }^{1} \cdot$ Michael Heethoff $^{1}$
}

Received: 14 September 2020 / Accepted: 18 December 2020 / Published online: 9 February 2021

(C) The Author(s) 2021

\begin{abstract}
Intensive land use has been shown to alter the composition and functioning of soil communities. Due to their low dispersal ability, oribatid mites are particularly vulnerable to landuse intensification and species which are not adjusted to management-related disturbances become less abundant. We investigated how different land-use parameters in forests and grasslands affect oribatid mite diversity and abundance, with a focus on: (1) species-level impacts, by classifying species as increasing ('winners') or decreasing ('losers') in abundance with higher land-use intensity, and (2) reproductive impact, by investigating whether sexual and parthenogenetic species react differently. We collected 32,542 adult oribatid mites in 60 forests and grasslands of known land-use intensity in two regions of Germany. Diversity and total abundance as well as the proportion of sexual species were higher in forests than in grasslands. Diversity declined with higher land-use intensity in forests, but increased with higher mowing and fertilization in grasslands. Depending on landuse parameter and region, abundance either declined or remained unaffected by increasing intensity. Gravidity was higher in sexual than in parthenogenetic species and sexuals had 1.6× more eggs per gravid female. Proportions of sexual species and gravid females decreased with land-use intensity in forests, but increased with mowing in grasslands. At the species level, $75 \%$ of sexuals and $87.5 \%$ of parthenogens were 'losers' of higher percentages of dead wood originating from management-related disturbances. Across land-use parameters and habitats, a similar proportion of sexual and parthenogenetic oribatid mite species were 'losers' of high land-use intensity. However, 'winner' species were more common among sexuals.
\end{abstract}

Keywords Biodiversity Exploratories · Land-use factors · Oribatid mites · Microarthropods $\cdot$ Sexuality $\cdot$ Parthenogenesis

Katja Wehner

kdwehner@gmx.de

Extended author information available on the last page of the article 


\section{Introduction}

Land-use intensification in forest and grassland habitats is often negatively correlated with the abundance and diversity of plant and animal taxa due to substantial changes in the environment (e.g., Altwood et al. 2008; Birkhofer et al. 2008; Culman et al. 2010; Allan et al. 2015). In agricultural systems, intensive mowing, grazing or fertilization causes the loss of soil organic matter and reduces the ability of soils to retain nutrients (Liiri et al. 2012; Birkhofer et al. 2012). In forests, intensive tree harvesting or the cultivation of non-native trees for the wood industry changes tree composition and influences the availability of resources in the soil food web system (Klarner et al. 2014). As these changes have a negative impact on biodiversity, the local and global impact of land-use intensity in forests and grasslands has increasingly been studied over recent decades (e.g., Marshall 2000; Allan et al. 2015; Birkhofer et al. 2012, 2017; Gossner et al. 2016; Penone et al. 2019).

The type and intensity of land-use vary in space and time and the associated degradation, fragmentation and conversion of habitats affect biota at different trophic levels (Newbold et al. 2005; Birkhofer et al. 2017). Arthropod richness, for instance, decreases with higher land-use intensity in agricultural ecosystems (Attwood et al. 2008; Culman et al. 2010; Chisté et al. 2016) and in highly managed forests (Zaitsev et al. 2002). Depending on the arthropod group, up to $50 \%$ of all species in a community were significantly less abundant under conditions of high land-use intensity (called 'losers'; Chisté et al. 2016, 2018; Mangels et al. 2017).

Microarthropods of soil and litter are important for ecosystem processes (e.g., Seastedt and Crossley 1981; Wallwork 1983; Norton 1990). Oribatid mites are among the smallest groups (about 100-1000 $\mu \mathrm{m}$ body length) inhabiting almost all terrestrial microhabitats around the world in high diversity and density (Schatz and Behan-Pelletier 2008; Maraun and Scheu 2000; Cianciolo and Norton 2006; Schatz et al. 2011). They are substantially involved in nutrient dynamics, play an important role in decomposition and affect porosity of soils, aeration, infiltration and the distribution of organic matter within soils (Bird et al. 2004). Oribatid mites interact with the microbial soil community which promotes nutrient availability and plant growth (Seastedt 1984; Marshall 2000). Oribatid mites have speciesspecific dispersal rates between 0.3 and $2.1 \mathrm{~cm}$ per day (Lehmitz et al. 2012) and several species cannot easily escape from unfavorable conditions (Behan-Pelletier 1999; Lindo and Visser 2004) and often show great decrease in abundances following disturbances (Seastedt and Crossley 1981).

A special trait of oribatid mites is the high percentage (about 10\%) of known or suspected parthenogenetic species (Norton and Palmer 1991). Theories predict that under certain environmental conditions sexual species have advantages over parthenogens due to the production of genetically diverse offspring (Maynard Smith 1978; Bell 1982; Lehtonen et al. 2012). On the other hand, advantages of parthenogenesis include a high reproductive potential due to the production of all-female offspring, no predation risk while mating and the maintenance of favorable gene combinations (Maynard Smith 1978; Bell 1982). However, whereas sex prevails in spatially heterogeneous habitats with diverse niches and structured resources in short supply, its advantage vanishes in the absence of resource limitation (Scheu and Drossel 2007; Maraun et al. 2019). The coexistence of sexual and parthenogenetic oribatid mite species in the same habitat allows the investigation if species with different reproductive modes are differently affected by increasing land-use intensity. When regular disturbances of their natural environment force oribatid mite species to quickly adapt to changing conditions, this may be realized by either producing genetically diverse 
offspring (sexuals) or by producing all-female populations to quickly (re-)colonize new or disturbed habitats (parthenogens; Lehmitz et al. 2012). The comparison of the current coexistence pattern among different land-use intensities can elucidate which reproductive mode performs better under certain conditions.

Belowground communities are proposed to be less sensitive to land-use intensity as the soil system buffers disturbances (Allan et al. 2015; Wolters 2001). Other studies found that mite community composition is affected by forest type (beech forests of different ages and coniferous stands; Erdmann et al. 2012; Maraun et al. 2012; Ehnes et al. 2014; Bluhm et al. 2016). In addition, effects of abiotic conditions such as soil $\mathrm{pH}$, carbon of soil and fine root content have also been shown (Birkhofer et al. 2012; Erdmann et al. 2012). However, comparisons of land-use effects among microhabitats (grassland vs. forests) are less frequent and studies have focused on general community measures, such as abundance and diversity. Few studies have looked at functional composition or different life-history strategies so far (but see Birkhofer et al. 2016, 2017).

In the present study, we briefly characterized oribatid mite communities in forest and grassland habitats in two regions of Germany (the Swabian Alb in the South and the Schorfheide-Chorin in the North-East). We focused on (1) what impact of land-use intensity can be seen on the species-level of oribatid mites, and (2) whether sexual and parthenogenetic oribatid mite species are differently affected. On the species level, we classified species as 'winners' if they significantly increase in abundance and occurrence with landuse intensity, whereas 'losers' significantly decrease (compared to a statistical null model). For comparing sexual and parthenogenetic oribatid mites, we determine the proportion of females within species, their proportion of gravidity and the numbers of eggs within gravid females as a measure of reproductive success. We tested whether the proportion of gravidity and numbers of eggs are affected by land use in grassland and forests. We further investigated whether sexual or parthenogenetic species can more easily cope with changing environmental conditions due to land-use management.

\section{Material and methods}

\section{Sampling sites}

Oribatid mites were collected from established forest and grassland plots in two regions of Germany in 2017: the Swabian Alb and the Schorfheide-Chorin. These comprise research areas established in the framework of the Biodiversity Exploratory project (http://www. biodiversity-exploratories.de; Fischer et al. 2010). The Swabian Alb is a low-mountain range in southwest Germany (460-860 m above sea level [a.s.1.], 09 $10^{\prime} 49^{\prime \prime}-09^{\circ} 35^{\prime}$ 54" $\mathrm{E} / 48^{\circ} 20^{\prime} 28^{\prime \prime}-48^{\circ} 32^{\prime} 02^{\prime \prime} \mathrm{N}$ ) having an annual precipitation of 800-930 mm and a mean temperature of $8-8.5^{\circ} \mathrm{C}$. The Schorfheide-Chorin (abbreviated Schorfheide) is a glacially formed landscape in northeast Germany (3-140 m a.s.1., $13^{\circ} 23^{\prime} 27^{\prime \prime}-14^{\circ} 08^{\prime} 53^{\prime \prime} \mathrm{E} / 52^{\circ} 47^{\prime}$ $25^{\prime \prime}-53^{\circ} 13^{\prime} 26^{\prime \prime} \mathrm{N}$ ), with an annual precipitation of $520-580 \mathrm{~mm}$ and a mean annual temperature of $6-7^{\circ} \mathrm{C}$.

Study plots are characterized by different intensities of land-use (Fischer et al. 2010; Blüthgen et al. 2012; Kahl and Bauhus 2014). In forests, plots are $100 \times 100 \mathrm{~m}$ in size. Parameters chosen to describe land-use comprise the proportion of harvested trees (Iharv), the proportion of non-native trees (Inonat) and the proportion of dead wood showing saw cuts (Idwcut). Iharv describes the proportion of harvested tree volume within a stand and 
is estimated by the presence of cut stumps and calculated as the ratio of harvested volume to the sum of standing, harvested and dead wood volume (Kahl and Bauhus 2014). Inonat is estimated as the proportion of harvested, living and dead wood volume of non-natural tree species to the sum volume of all tree species. Idwcut represents the proportion of dead wood with saw cuts to the total amount of dead wood (Kahl and Bauhus 2014). These three parameters are combined in a forest management index (Formi) and equally weighted (Kahl and Bauhus 2014). Formi, Iharv, Inonat and Idwcut were obtained from the Bexis database for the year 2016 (Online Appendix 1; ID 20055, owners: J. Hailer, U. Pommer, F. Van Broeck, M. Ayasse, V. Eisenbach).

In grasslands, plots are $50 \times 50 \mathrm{~m}$ in size. Land-use parameters for grasslands comprise fertilization intensity ( $\mathrm{kg}$ nitrogen $\mathrm{ha}^{-1} \mathrm{year}^{-1}$ ), the mowing frequency per year and livestock grazing (livestock units*days of grazing ha ${ }^{-1}$ year $^{-1}$ ), all combined in the land-use index LUI (Blüthgen et al. 2012). Data were obtained from the Bexis database and averaged for the years 2015 and 2016 (Online Appendix 1; ID 19266, owners: K. Lorenzen, W. Weisser, M. Ayasse, M. Fischer, J. Vogt).

\section{Sampling method}

In 2017, soil samples were taken from a total of 60 plots in the Swabian Alb and the Schorfheide: 15 forest and 15 grassland plots in each of the regions. Plots, which were at least $5 \mathrm{~km}$ apart, were chosen according to their land-use intensity (Formi in forests and LUI in grasslands) to cover a complete gradient from low to high intensity (Online Appendix 1). Sampling was replicated $5 \times$ per plot, at the south-east, south-west and north-west corners and in the middle of the two included edges, resulting in 300 samples in total. Each soil sample $(20 \times 20 \mathrm{~cm}$ in grasslands, $15 \times 15 \mathrm{~cm}$ in forests, all $3 \mathrm{~cm}$ deep) was cut from the substrate using a sharp knife and included the surface materials, such as herbaceous vegetation, dead litter, mosses and pieces of wood.

Samples were directly transferred to the laboratory and oribatid mites were extracted by heat (increasing from 20 to $50{ }^{\circ} \mathrm{C}$ with $2{ }^{\circ} \mathrm{C} \mathrm{h}^{-1}$ ) using a modified Kempson extractor for $48 \mathrm{~h}$ and collected into $75 \%$ ethanol (Kempson et al. 1963). Adult individuals were identified to species level whenever possible (not done for most Brachychthoniidae, Phthiracaridae and Suctobelbidae) using the identification key of Weigmann (2006). Sex was determined and, for females, the eggs were counted. Reproductive mode-sexual or parthenogenetic-was assigned to each species based on the sex ratio (assumed sexual if at least $20 \%$ of collected mites were male) or inferred from the literature (Norton and Palmer 1991; Cianciolo and Norton 2006; Domes et al. 2007; Wehner et al. 2018). Furthermore, mean body size of species was inferred from Weigmann (2006). Data are deposited at the Bexis database ID 26446 and openly available under https://doi.org/10.25829/bexis.26446 -3 .

\section{Statistical analysis}

\section{Oribatid mite assemblages}

All statistical analyses were performed with R v.3.5.2 (R Core Team 2018). We characterized oribatid mite assemblages by species diversity and abundance and compared habitats (forest vs. grassland) and regions (Swabian Alb vs. Schorfheide) using non-metric multidimensional scaling (NMDS). We used Jaccard as a dissimilarity index for the complete 
assemblage and sexual species but Horn-Morisita dissimilarity index for parthenogenetic species. NMDS was calculated with two dimensions $(\mathrm{k}=2)$ using the function 'metaMDS' in the R package 'vegan' (Oksanen et al. 2019). We further calculated the community weighted mean (CWM) of oribatid mite body size per plot.

Numbers of collected individuals were standardized to abundances per $\mathrm{m}^{2}\left(\mathrm{Ind} / \mathrm{m}^{2}\right)$ and number of species was used for calculating the effective Shannon diversity ( $\mathrm{e}^{\mathrm{H}}$; Jost 2006). Normal distribution and homogeneity of variances of residiuals were tested using the Shapiro and Levene test, respectively. Data were $\log (\mathrm{x}+0.1)$ transformed if necessary.

To compare oribatid mite assemblages among regions and habitats, Shannon diversity, density and the size CWM were analyzed as response variables, whereas region (Swabian Alb, Schorfheide) and habitat (forest, grassland) were fixed as explanatory variables using ANOVA followed by Tukey's pairwise test. Plot was implemented as random factor.

\section{Mode of reproduction, sex ratios and number of eggs}

Proportions of sexual and parthenogenetic species and individuals, respectively, as well as the proportion of females per species (sex ratio) were analysed as response variables using generalized linear models (glm) with binomial distribution. Numbers of eggs per gravid female were analysed as response variable using glm with Poisson distribution. Plot was implemented as random factor.

\section{Influence of land-use intensity}

The effects of land use on diversity, abundance, size CWM, proportion of females, proportion of gravidity and number of eggs were tested for the combined land-use indices (Formi in forests, LUI in grasslands) as well as for their respective sub-parameters (Online Appendix 1).

Using linear regressions, we tested the response of mite diversity, mite abundance and CWM of body size to changes in the land-use parameters. The response of the proportion of sexual individuals, the proportion of females therein and the number of eggs in gravid females to changes in the land-use parameters were tested using general linear model with binomial and Poisson distribution, respectively.

Moreover, we calculated each species' 'environmental niche' along the gradient of landuse intensity within each habitat. The niche optimum was calculated as the abundanceweighted mean (AWM) for species $i$ as

$$
A W M_{i}=\sum_{p=1}^{15} L_{p} \cdot \frac{a_{i, p}}{A_{i}},
$$

where $L_{p}$ is the land-use gradient value of plot $p, a_{i, p}$ the abundance of species $i$ in plot $p$ and $A_{i}$ the total abundance of species $i$ across all 15 forest or 15 grasslands sites, respectively (Chisté et al. 2016).

As a proxy for the 'niche breadth' of each species, we also calculated the abundanceweighted standard deviation (AWSD) for each land-use index and sub-parameter analogously. To test whether AWMs and AWSDs statistically deviate from an expected random distribution, we compared the calculated values against the expected values obtained from a null model that distributes each species across $N_{i}$ sites with the same probability, with $N_{i}$ being the number of sites in which species $i$ was found. The null model thus chooses values of the focal land-use parameter (LUI, Formi, single components) of $N_{i}$ sites and calculates 
a distribution of predicted AWMs and AWSDs values for each species based on 10,000 iterations. The null model was restricted to the one or two regions in which the species was recorded, to allow for potential distribution boundaries of each species in Germany that may not be related to plot conditions.

As in any randomization model, the percentage of AWMs or AWSDs from 10,000 null models with expected values greater or smaller than those observed, provides the $P$-value for the significance of the deviation between observed and expected values. A 'winner' is defined as a species with an observed AWM larger than the upper 5\% of the distribution of AWMs obtained by the null models (i.e., associated with higher-than-average landuse intensity), a 'loser' shows an observed AWM smaller than the lower 5\% (low landuse intensity specialist). For species that could be classified as neither 'loser' nor 'winner', we tested whether they are specialized on intermediate land-use or abiotic levels, that is, whether they have an intermediate AWM with a narrower niche than expected. Therefore, we compared the observed and expected weighted coefficient of variation (CV $=$ AWSD/ AWM) to account for the increase in standard deviation with increasing mean. This comparison allows us to distinguish 'opportunists' (observed $\mathrm{CV} \geq$ expected $\mathrm{CV}$ ) from species that are 'specialized' on intermediate land-use intensities (observed CV $<$ expected CV and species not only occurring on one site, i.e., $C V \neq 0$ ). As the definition of a weighted mean and weighted standard deviation is per se mathematically independent of the total abundance or total number of plots, rare species can be kept in the analysis.

\section{Results}

\section{Habitat comparison}

\section{Oribatid mite assemblages}

In total, 17,611 adult oribatid mite individuals were collected in the Swabian Alb and 14,931 in the Schorfheide, belonging to 100 taxa in total (Table 1). In the Swabian Alb, 72 taxa were found in forests (15 parthenogenetic, 57 sexual) and 62 in grasslands (15 parthenogenetic, 47 sexual). Species richness was slightly lower in the Schorfheide; in forests, 70 taxa (25 parthenogenetic, 45 sexual) and in grasslands 34 taxa (8 parthenogenetic, 26 sexual) were represented. Similarly, oribatid mite diversity was consistently higher in forests than in grasslands albeit lower in the Schorfheide than in the Swabian Alb (Fig. 1; habitat: $\mathrm{F}_{1,287}=124.839$; region: $\mathrm{F}_{1,287}=37.112$, both $\mathrm{p}<0.001$ ).

NMDS analysis, including sexually and parthenogenetically reproducing oribatid mite species, clearly separated habitats and regions (Fig. 2a). However, assemblages were more similar to each other in the same habitat of different regions than among habitats in one region. NMDS analysis of sexual species revealed a similar pattern with a broader overlap of forest assemblages (Fig. 2b). In contrast, oribatid mite assemblages of parthenogenetic species were highly similar (Fig. 2c). The pattern of similar assemblages in similar habitats among regions is also present in the size CWM (Fig. 3; habitat: $\mathrm{F}_{1,56}=113.838$, $\mathrm{p}<0.001$; region: $\mathrm{F}_{1,56}=3.268, \mathrm{p}=0.076$ ). Assemblages in forests comprise smaller species than in grasslands which was more pronounced in the Schorfheide than in the Swabian Alb (habitat*region: $\mathrm{F}_{1,56}=6.558, \mathrm{p}=0.013$ ).

In both regions, the majority of adult oribatid mite individuals occurred in forests; this pattern was more pronounced in the Schorfheide (74.8 and 89\%, respectively; Fig. 4 


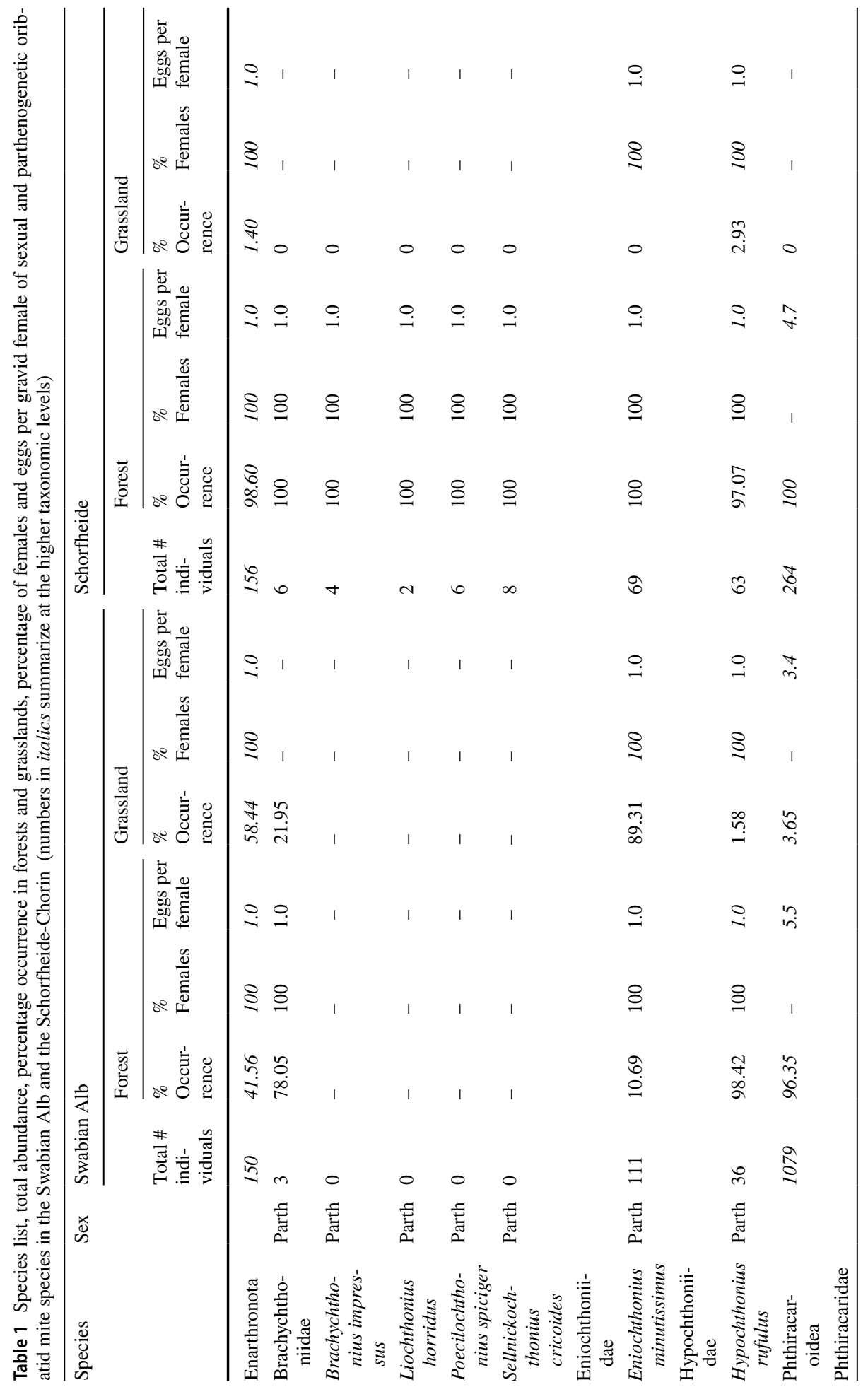




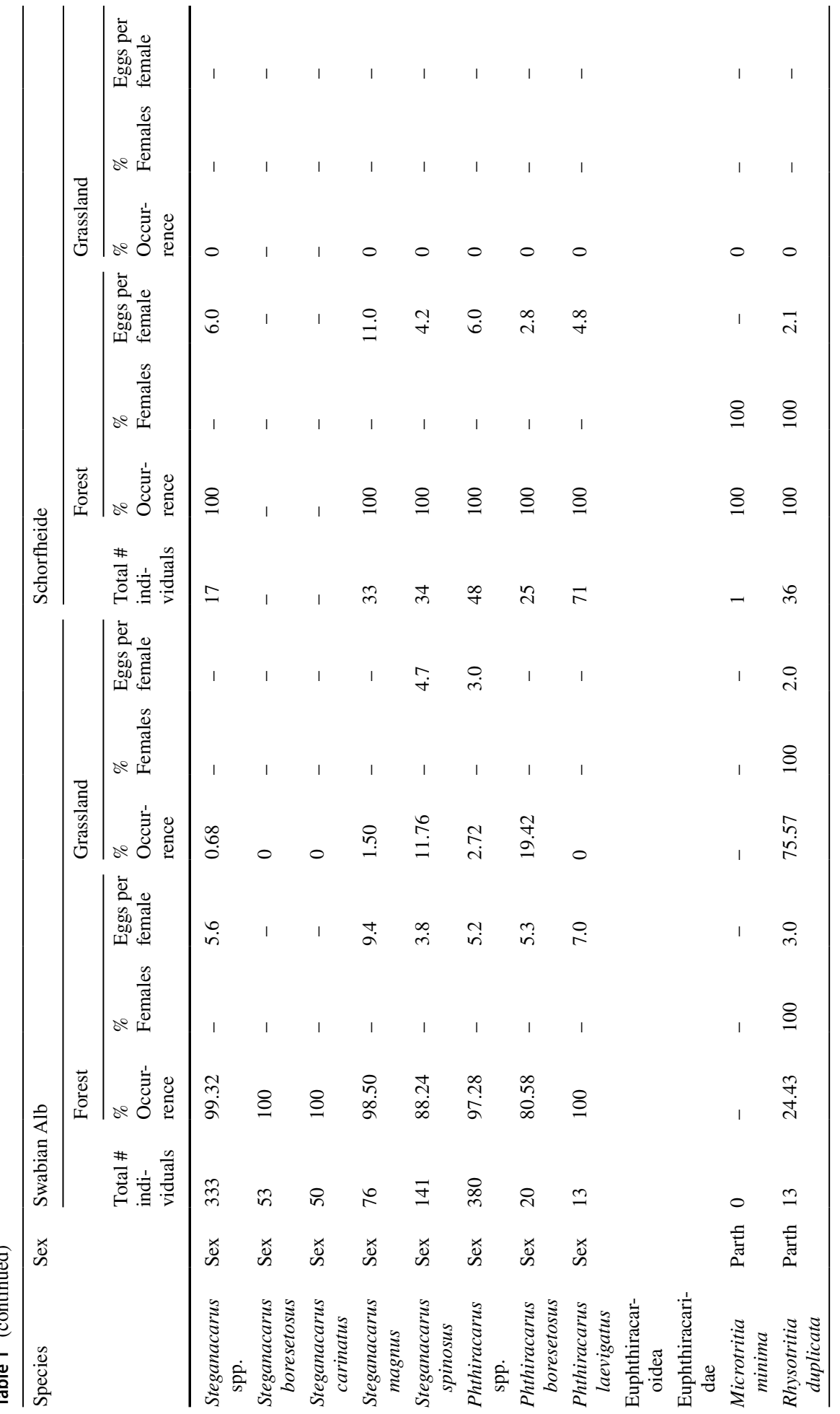




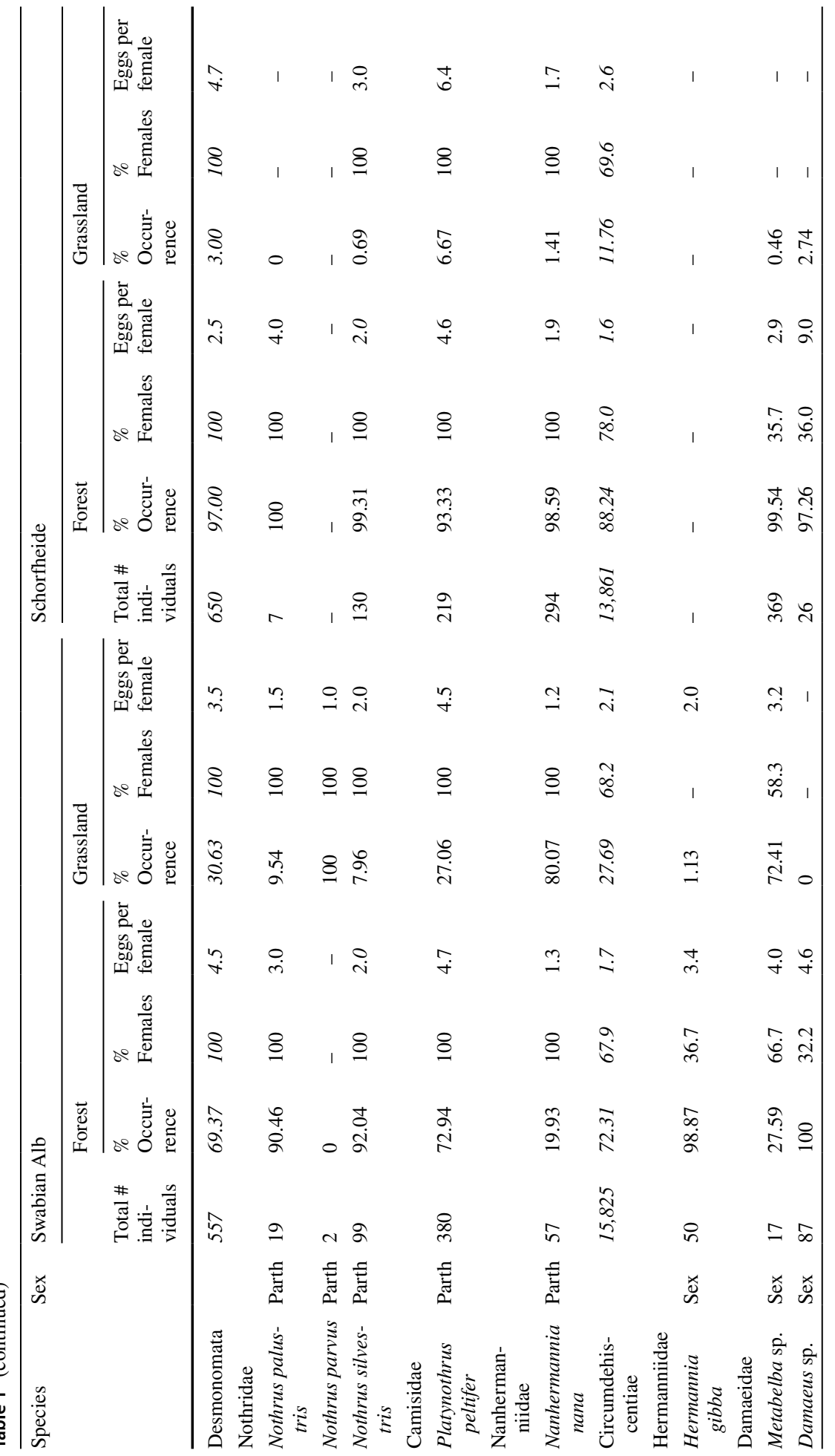




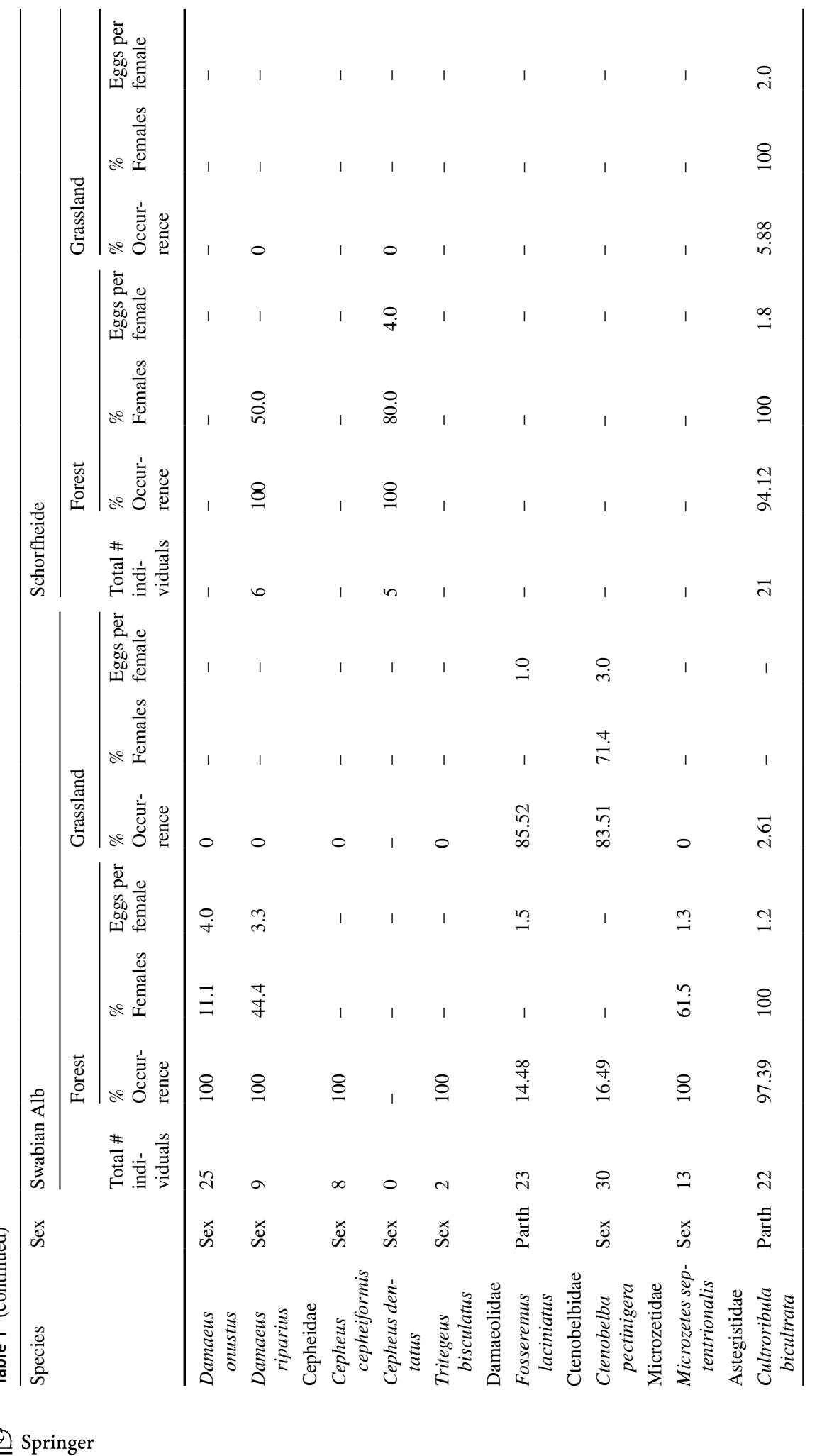




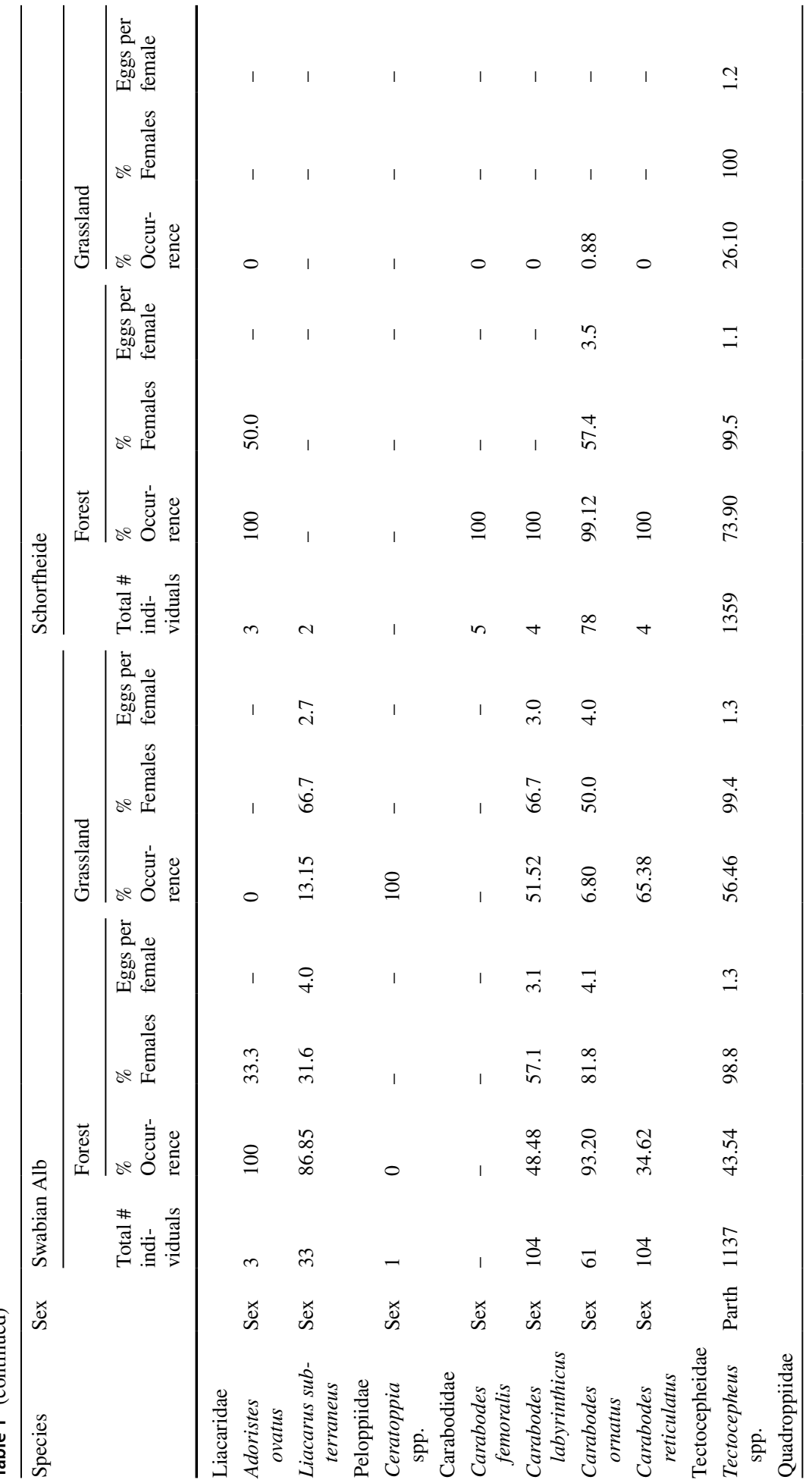




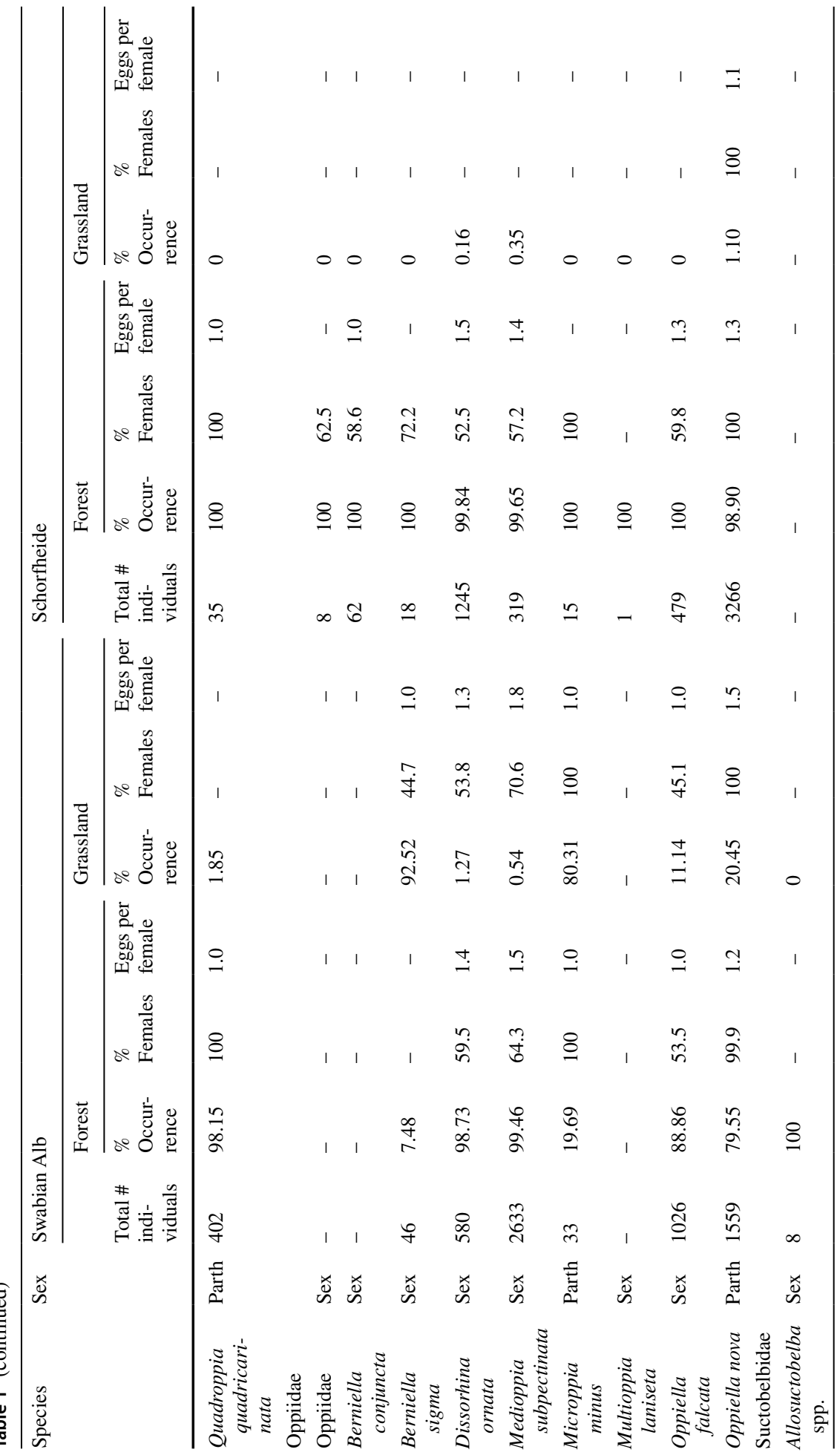




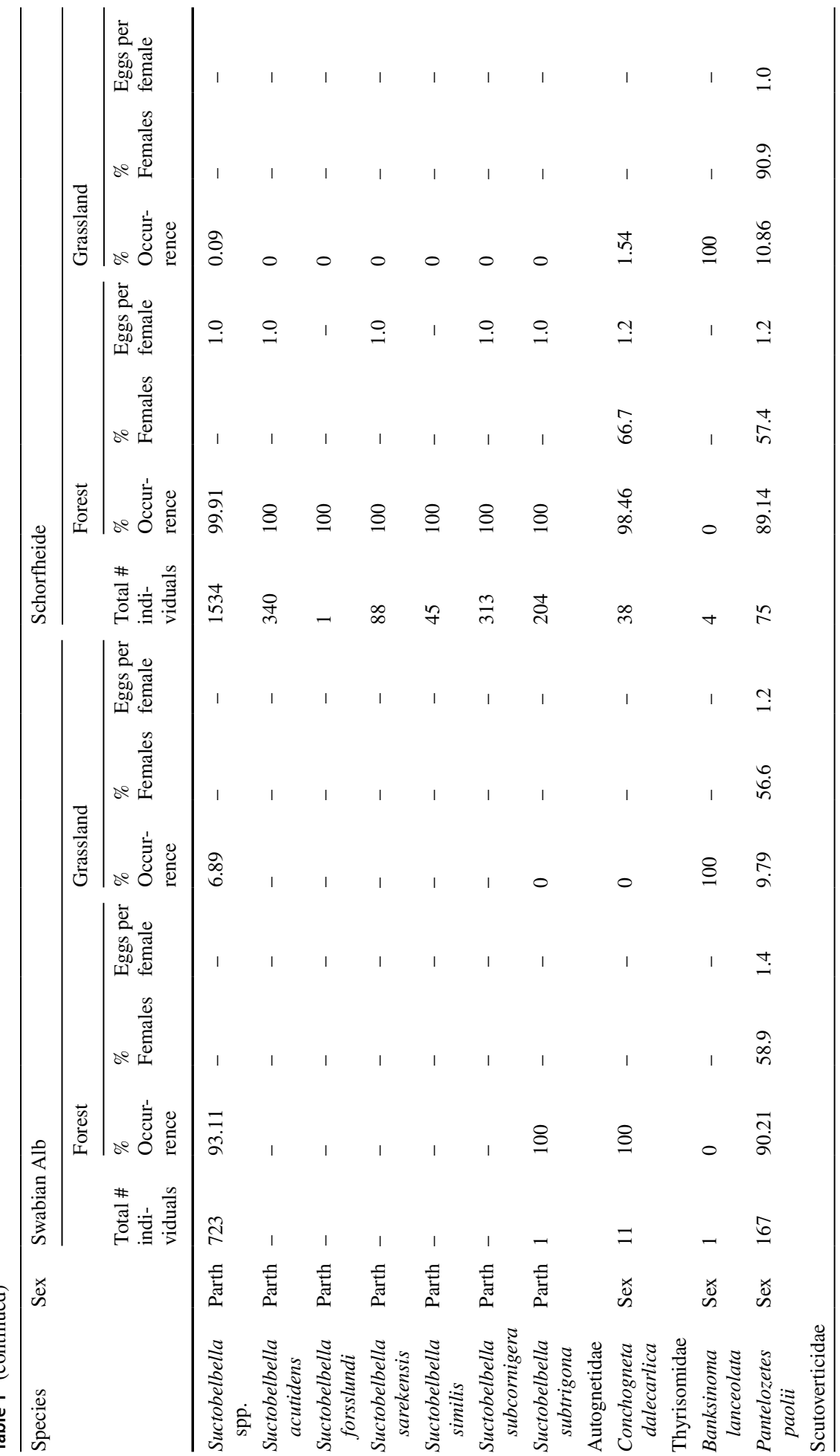




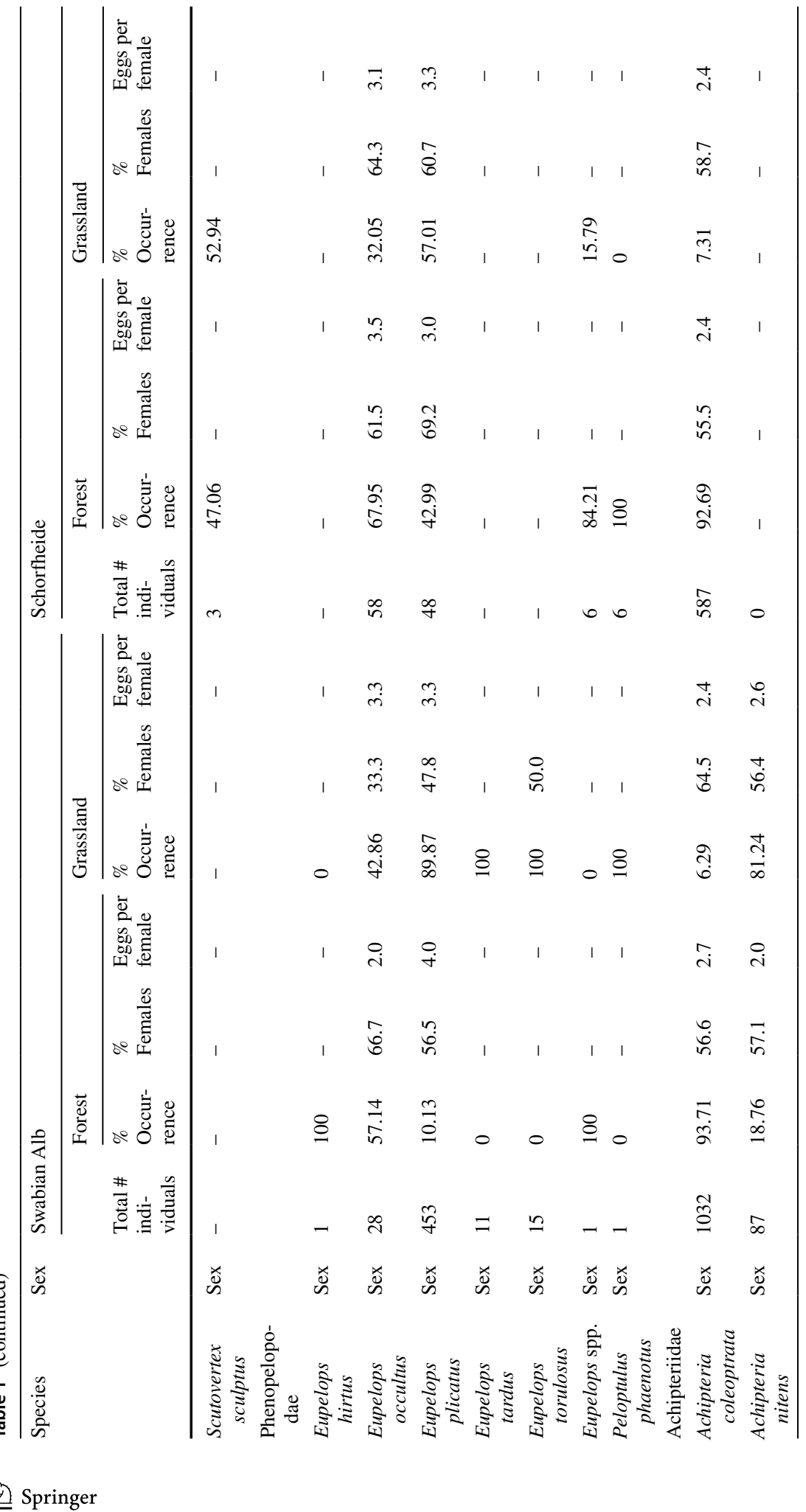




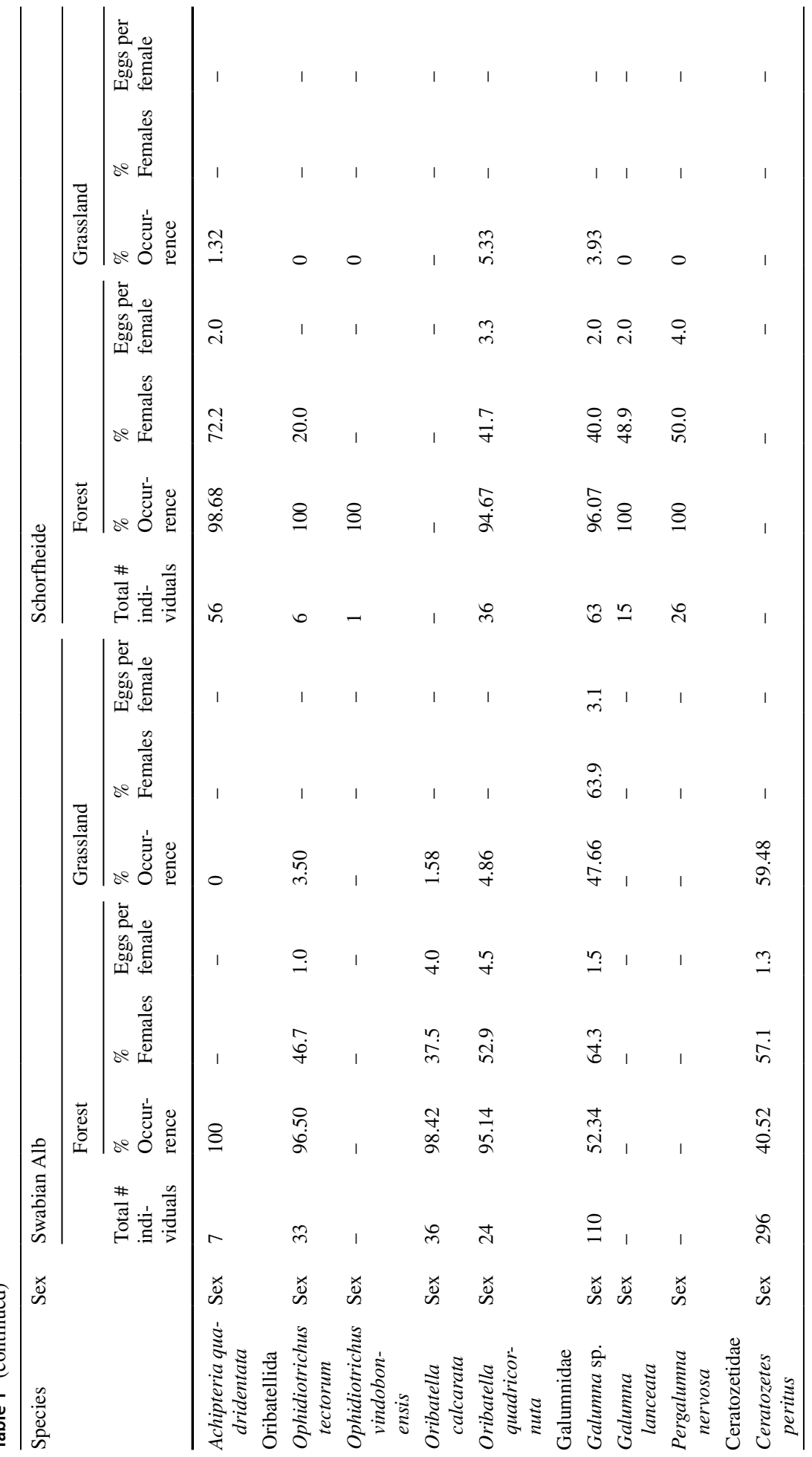




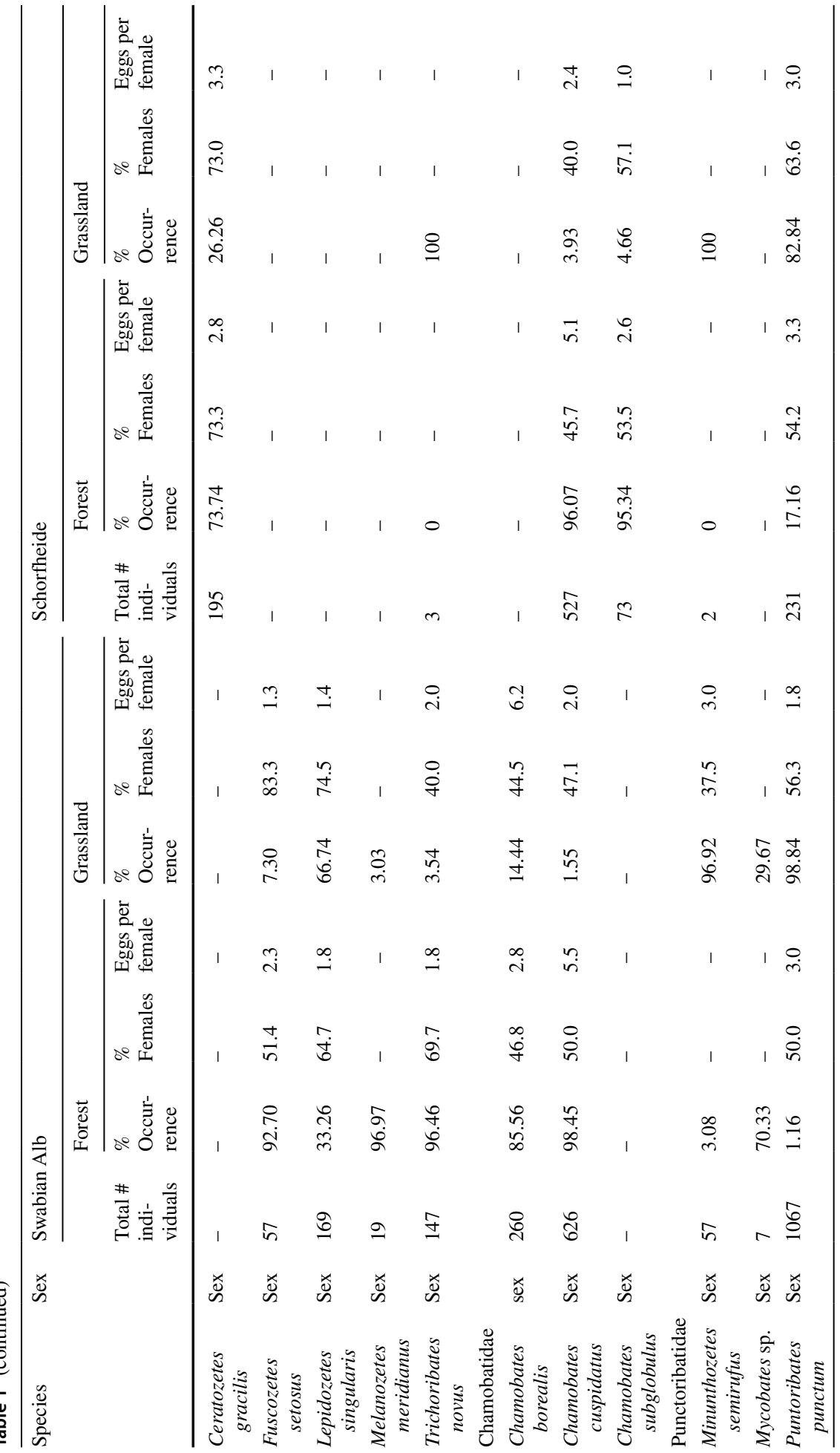




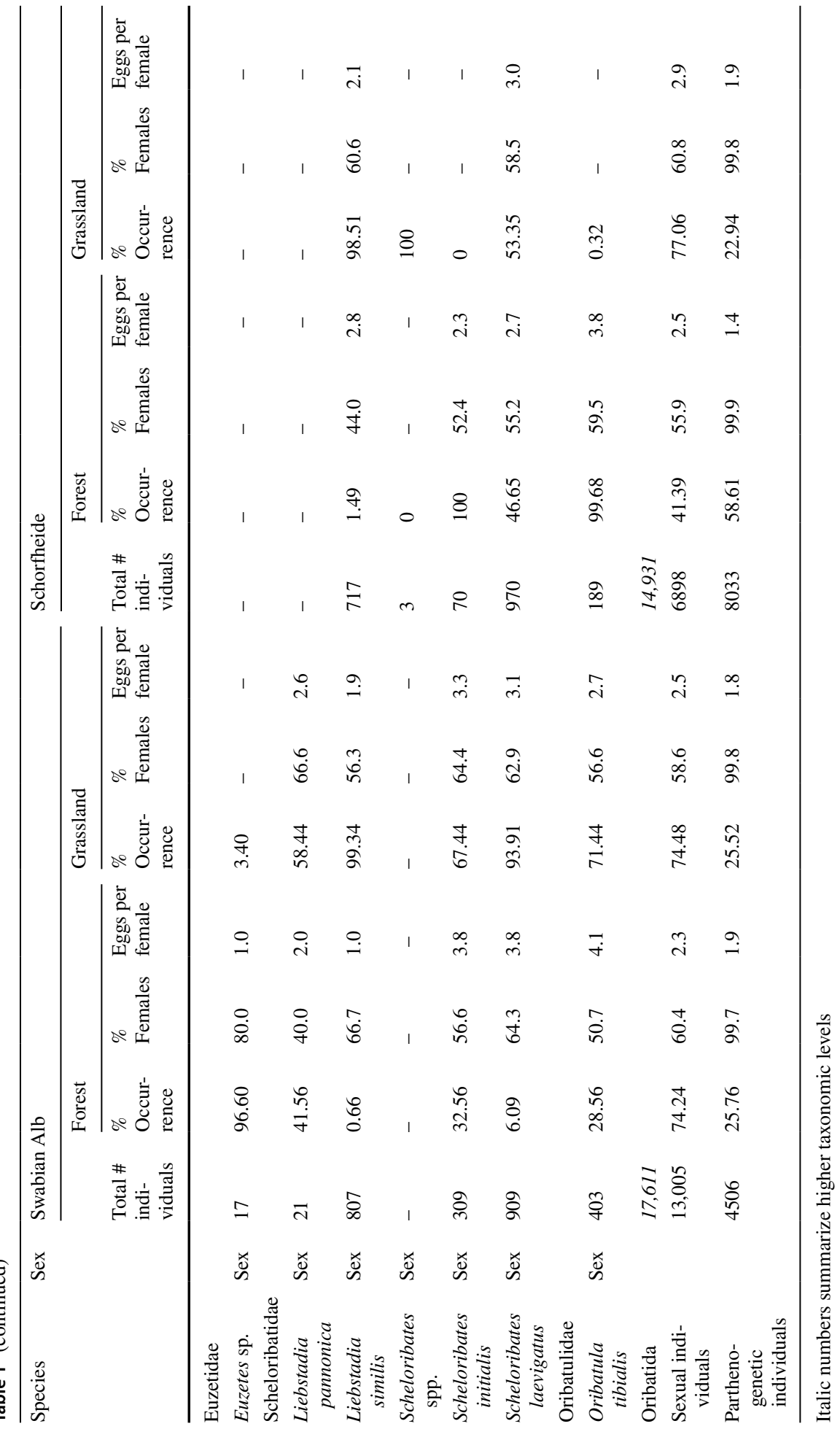


Fig. 1 Effective Shannon diversity of oribatid mite communities in forest und grassland habitats in the Swabian Alb and the Schorfheide-Chorin. The black line within the boxplots represents the median of data, the upper and lower boxes the $75 \%$ and $25 \%$ quantile, respectively, and the whiskers $1.5 \times$ the interquartile range; outliers are represented by dots

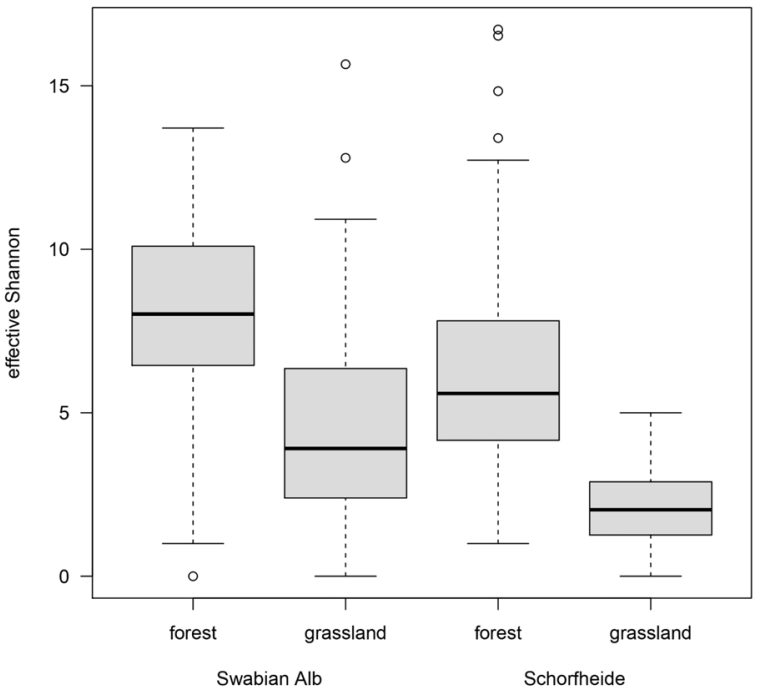

middle; habitat: $\mathrm{F}_{1,287}=64.672, \mathrm{p}<0.001$; region: $\mathrm{F}_{1,287}=4.7, \mathrm{p}=0.031$; habitat*region: $\left.\mathrm{F}_{1,287}=4.805, \mathrm{p}=0.029\right)$.

\section{Mode of reproduction, sex ratio and number of eggs}

The percentages of sexual and parthenogenetic individuals and species were similar in grassland and forest habitats in the Swabian Alb and in grasslands in the Schorfheide: with about $75 \%$, sexuality dominated over parthenogenesis (Fig. 4 left and right). By contrast, Schorfheide forests had a higher percentage of parthenogenetic individuals $(58.6 \%)$ and a relatively high percentage of parthenogenetic species (37.3\%) (Table 2).

The percentage of females in sexual and parthenogenetic oribatid mite communities significantly differed with the reproductive mode and region (Fig. 5, Table 3). In sexual species 55.3 and 54.9\% females were present in the Swabian Alb and the Schorfheide, respectively. The parthenogenetic part of the oribatid mite community had almost $100 \%$ females in grasslands and had only a few males in forests (99.95\% females).

The sex ratio of parthenogenetic and sexual species in forest and grassland communities was consistent among regions (Table 1). In sexual species, sex ratios varied between ca. 30\% (Ophidiotrichus tectorum, Oribatella calcarata, Hermannia gibba, Damaeus spp.) and $70 \%$ females (Ceratozetes gracilis, Achipteria quadridentata; Table 1) and averaged at about 59\%. Parthenogenetic species normally comprised $100 \%$ females, but rare, spanandric males were found in the genus Tectocepheus and in Oppiella nova (Table 1).

The average percentage of gravid female was generally higher in sexual than in parthenogenetic species (71 vs. 63\%) and higher in the Swabian Alb than in the Schorfheide (72 vs. 62\%; Fig. 6, Table 4). In both habitats and both regions, sexual species had significantly more eggs per gravid female than parthenogenetic species (2.97 vs. 1.81 on average; Fig. 7, Table 5). 
(a) Sexual and parthenogenetic oribatid mite species

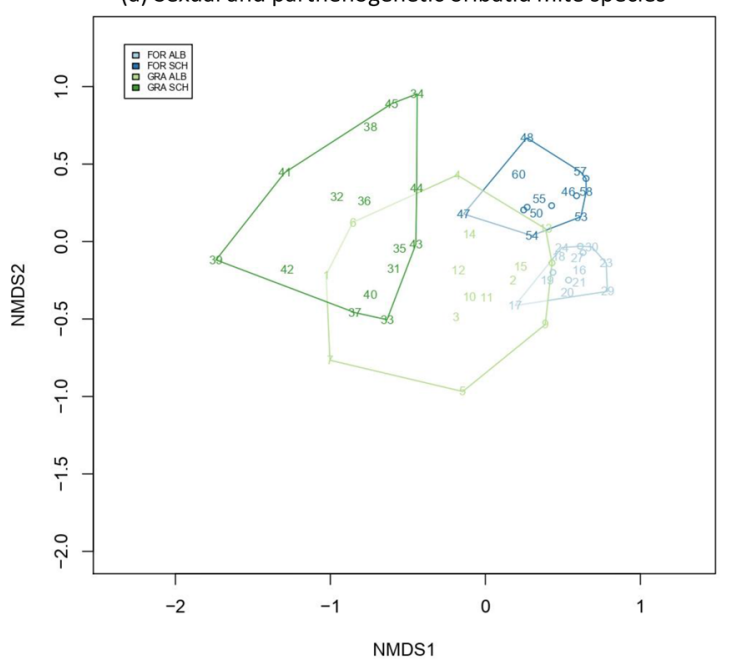

(b) Sexual oribatid mite species

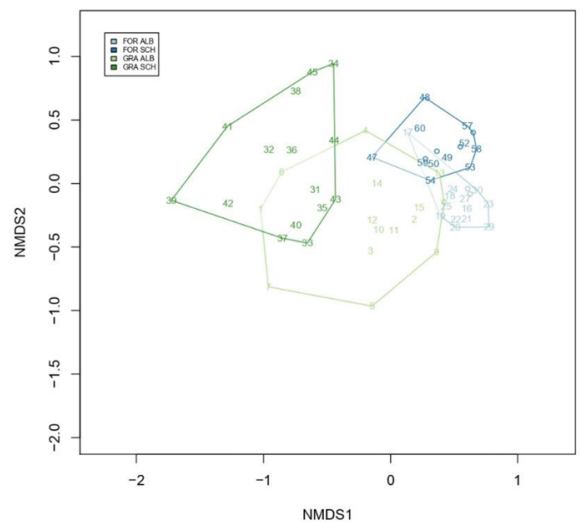

(c) Parthenogenetic oribatid mite species

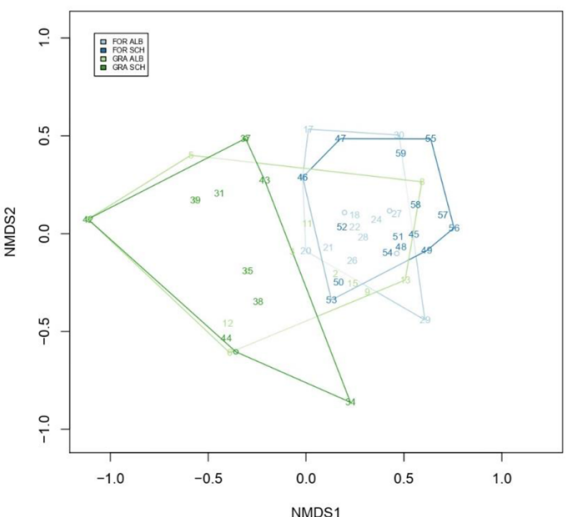

Fig. 2 Non-metric multidimensional scaling (NMDS) for a sexual and parthenogenetic (Jaccard distance, $\mathrm{k}=2$ ), b sexual (Jaccard distance, $\mathrm{k}=2$ ) and $\mathbf{c}$ parthenogenetic (Horn distance, $\mathrm{k}=2$ ) oribatid mite assemblages in forests and grasslands in the Swabian-Alb and the Schorfheide-Chorin. Light blue: forest (FOR) in the Swabian Alb (ALB), blue: forest (FOR) in the Schorheide-Chorin (SCH), light green: grassland (GRA) in the Swabian Alb (ALB), green: grassland (GRA) in the Schorheide-Chorin (SCH)

\section{Influence of land-use intensity}

The community weighted mean (CWM) of body sizes was not affected by any land-use parameter neither in forests nor in grasslands (Table 6, for statistical values see Online Appendix 2). Diversity of oribatid mite assemblages correlated negatively with all forestmanagement parameters except wood harvesting in the Swabian Alb, and with the proportion of dead wood with saw cuts and the combined forest-management index in the Schorfheide (Table 6, Online Appendix 3). In grasslands, land-use intensity had a stronger impact on oribatid mite diversity than on density. In both regions, diversity was significantly lower 
Fig. 3 Community weighted mean of body size of oribatid mite assemblages in forest and grassland habitats in the Swabian Alb and the Schorfheide-Chorin. The black line within the boxplots represents the median of data, the upper and lower boxes the $75 \%$ and $25 \%$ quantile, respectively, and the whiskers $1.5 \times$ the interquartile range; outliers are represented by dots
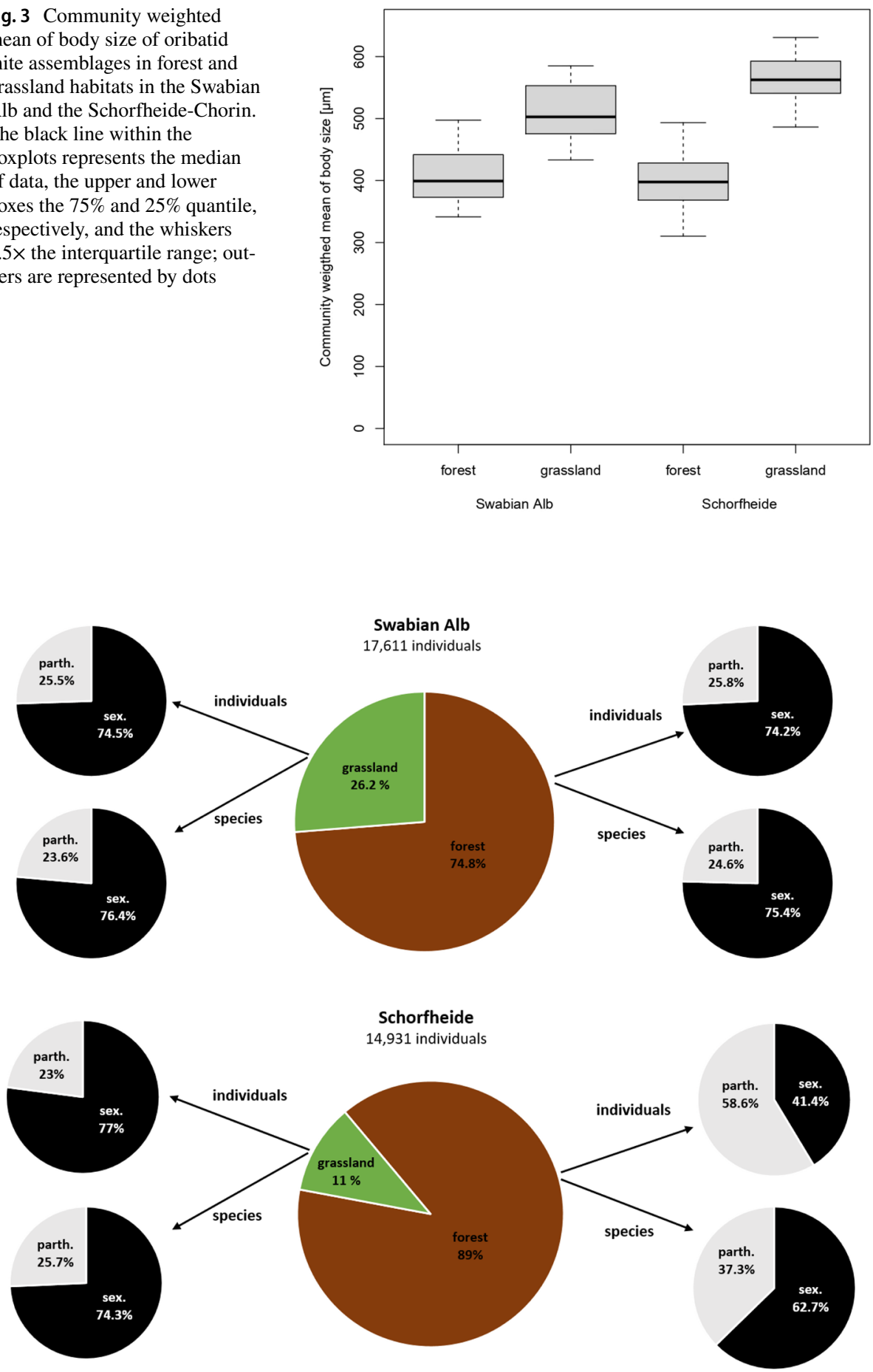

Fig. 4 Percentage distribution of total oribatid mite individuals, sexual (sex.) and parthenogenetic (parth.) individuals and species in forest and grassland habitats in the Swabian Alb and the Schorfheide-Chorin 
Table 2 Statistical analysis of the reproductive mode (sexual vs parthenogenetic) among habitats (forest vs grassland) and regions (Swabian Alb vs SchorfheideChorin)

\begin{tabular}{lllrr}
\hline & Df & denDf & \multicolumn{1}{l}{ F } & p \\
\hline Sex & 1 & 69 & 4.604 & 0.035 \\
Habitat & 1 & 70 & 25.843 & $<0.001$ \\
Region & 1 & 70 & 0.036 & 0.85 \\
Habitat:Sex & 1 & 69 & 14.353 & $<0.001$ \\
Region:Sex & 1 & 69 & 5.660 & 0.020 \\
Region:Habitat & 1 & 70 & 5.317 & 0.024 \\
Region:Habitat:Sex & 1 & 69 & 6.865 & 0.011 \\
Intercept & 1 & 70 & 223.773 & $<0.001$ \\
\hline
\end{tabular}

$D f$ degrees of freedom, den denominator
Fig. 5 Percentage of females in sexual and parthenogenetic oribatid mite species in forest and grassland habitats in the Swabian Alb and the Schorfheide-Chorin. The black line within the boxplots represents the median of data, the upper and lower boxes the $75 \%$ and $25 \%$ quantile, respectively, and the whiskers $1.5 \times$ the interquartile range; outliers are represented by dots

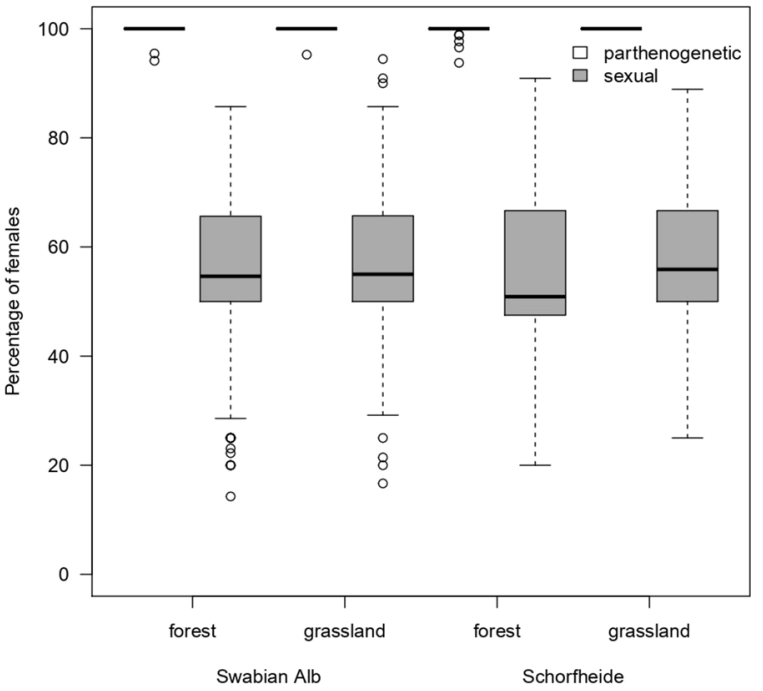

Table 3 Statistical analysis (general linear model with binomial distribution) of the percentage of females within sexual and parthenogenetic oribatid mite species among forests and grasslands habitats in the Swabiab Alb and the Schorfheide-Chorin

\begin{tabular}{lcccccc}
\hline & Df & Deviance & Resid. Df & Resid. Dev & F & p \\
\hline Sex & 1 & 540.87 & 2375 & 1128 & 1258.1 & $<0.001$ \\
Habitat & 1 & 0.98 & 2374 & 1127 & 2.288 & 0.13 \\
Region & 1 & 0.85 & 2373 & 1126.1 & 1.972 & 0.16 \\
Sex:Habitat & 1 & 1.45 & 2372 & 1124.7 & 3.369 & 0.067 \\
Sex:Region & 1 & 3.49 & 2371 & 1121.2 & 8.118 & 0.004 \\
Habitat:Region & 1 & 0.63 & 2370 & 1120.6 & 1.463 & 0.23 \\
Sex:Habitat:Region & 1 & 0.00 & 2369 & 1120.6 & 0.004 & 0.95 \\
& & & 2376 & 1668.8 & &
\end{tabular}

$D f$ degrees of freedom, Resid. residuals, Dev deviation 
Fig. 6 Percentage of gravid females in sexual and parthenogenetic oribatid mite species in forest and grassland habitats in the Swabian Alb and the Schorfheide-Chorin. The black line within the boxplots represents the median of data, the upper and lower boxes the $75 \%$ and $25 \%$ quantile, respectively, and the whiskers $1.5 \times$ the interquartile range; outliers are represented by dots
Table 4 Statistical analysis (general linear model with binomial distribution and plot as random factor) of the percentage of gravid females among different habitats (forest vs grassland) and regions (Swabian Alb vs Schorfheide-Chorin)

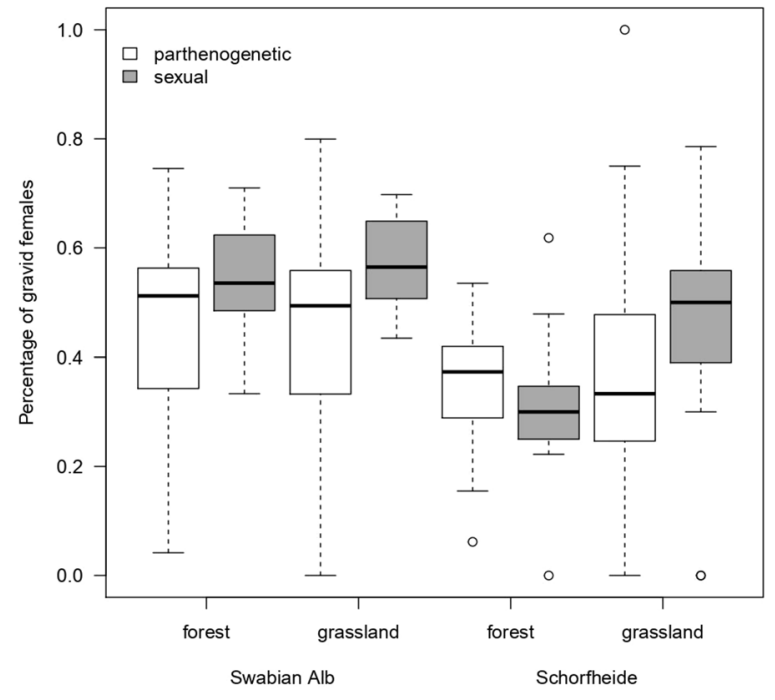

\begin{tabular}{lllrr}
\hline & Df & denDf & F & p \\
\hline Sex & 1 & 69 & 4.759 & 0.033 \\
Habitat & 1 & 70 & 3.268 & 0.075 \\
Region & 1 & 70 & 22.755 & $<0.001$ \\
Sex:Habitat & 1 & 69 & 2.509 & 0.12 \\
Sex:Region & 1 & 69 & 1.223 & 0.27 \\
Habitat:Region & 1 & 70 & 1.855 & 0.18 \\
Sex:Habitat:Region & 1 & 69 & 0.713 & 0.40 \\
Intercept & 1 & 70 & 864.171 & $<0.001$ \\
\hline
\end{tabular}

$D f$ degrees of freedom, den denominator

on plots with a high land-use index and in the Swabian Alb additionally on plots with high grazing intensity. In contrast, diversity was correlated positively with high mowing and fertilization intensity in the Schorfheide (Table 6, Online Appendix 3).

In the Schorfheide, oribatid mite density significantly dropped with increasing proportion of dead wood with saw cuts in forests and with higher grazing and fertilization intensity in grasslands (Table 6, Online Appendix 3). However, density in the Swabian Alb was unaffected by either grassland or forest land-use parameters.

A high forest management index and a high number of non-native trees significantly correlated with lower proportion of sexual individuals in forests in the Swabian Alb, but mowing in grasslands was positively correlated with the proportion of sexual individuals in the Schorfheide (Table 6, Online Appendix 4). Accordingly, the proportion of females in sexual species was only affected in grasslands in the Schorfheide; the proportion of females was lower at high land-use indexes and high grazing intensity whereas intensive mowing was correlated positively with the proportion of females in sexual species.

In sexual species, the proportion of gravid females dropped with an increasing number of non-native trees, tree harvesting and dead wood with saw cuts; in grasslands, a higher 
Fig. 7 Numbers of eggs in gravid females in sexual and parthenogenetic oribatid mite species in forest and grassland habitats in the Swabian Alb and the Schorfheide-Chorin. The black line within the boxplots represents the median of data, the upper and lower boxes the $75 \%$ and $25 \%$ quantile, respectively, and the whiskers $1.5 \times$ the interquartile range; outliers are represented by dots

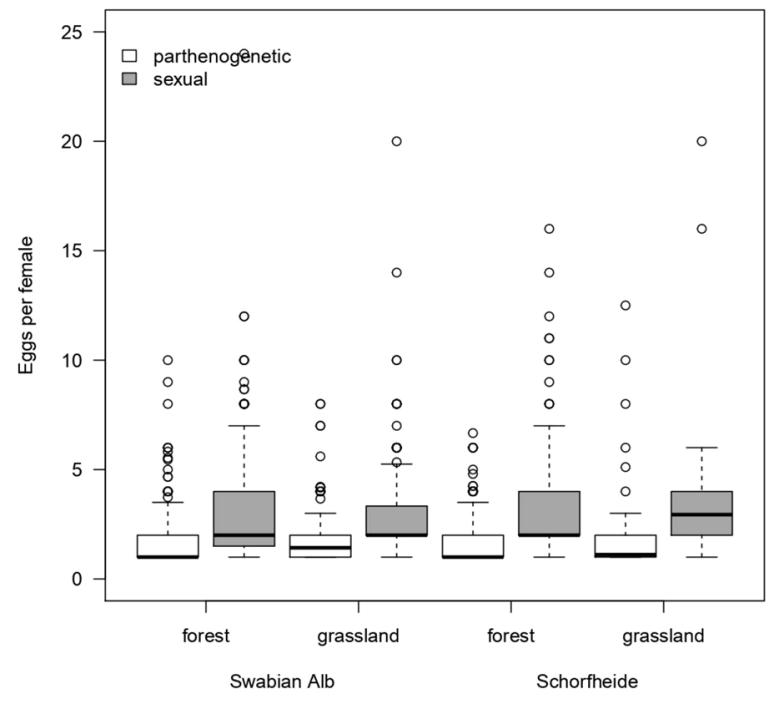

Table 5 Statistical analysis (general linear model with poisson distribution) of eggs per gravid female in sexual and parthenogenetic oribatid mite species in forests and grasslands in the Swabian Alb and the Schorfheide-Chorin

\begin{tabular}{lcccc}
\hline & Df & Deviance & F & p \\
\hline Sex & 1 & 180.01 & 180.098 & $<0.001$ \\
Habitat & 1 & 0.092 & 0.092 & 0.76 \\
Region & 1 & 0.242 & 0.242 & 0.62 \\
Sex: Habitat & 1 & 4.926 & 4.926 & 0.026 \\
Sex: Region & 1 & 6.094 & 6.094 & 0.014 \\
Habitat: Region & 1 & 5.177 & 5.177 & 0.023 \\
Sex: Habitat:Region & 1 & 2.536 & 2.536 & 0.11 \\
\hline
\end{tabular}

$D f$ degrees of freedom

proportion of gravid females was present on plots with high fertilization (Table 6, Online Appendix 5). In parthenogenetic species, gravidity positively correlated with high fertilization in the Swabian Alb and with high mowing intensity in the Schorfheide. However, the number of eggs per gravid female in sexual species was not influenced by any land-use parameter. In parthenogens, numbers of eggs per gravid female increased in the Swabian Alb but decreased in the Schorfheide with increasing tree harvesting.

On the species level, land-use effects in forests were more pronounced than those in grasslands (Table 7, Online Appendix 6). In sexual species, about 6\% were significant 'losers' to a high forest management index and about 4 and $7 \%$, respectively, were 'losers' to tree harvesting and the proportion of non-native trees. A high proportion of dead wood with saw cuts had by far the greatest impact, resulting in 75\% 'losers' among sexual species. Similarly, a high percentage of dead wood with saw cuts was correlated negatively with $87.5 \%$ of parthenogenetic species. 'Winner' species were more abundant in sexuals than in parthenogens, especially for the forest management index (about 12\%) and the percentage of non-native trees (about 10\%).

In grasslands, we found only about $2 \%$ 'losers' in sexual species concerning the combined land-use index. On the other hand, about 7, 4 and 2\% 'winners' were present in 
Table 6 Influence of the land-use parameters forest management index (Formi), proportion of non-native trees (Inonat), proportion of dead wood with saw cuts (Idwcut) and the proportion of harvested trees (Iharv) in forests and the land-use index (LUI), grazing, mowing and fertilization in grasslands

\begin{tabular}{|c|c|c|c|c|}
\hline & \multicolumn{2}{|l|}{ Forest } & \multicolumn{2}{|l|}{ Grassland } \\
\hline & Swabian Alb & Schorfheide & Swabian Alb & Schorfheide \\
\hline \multicolumn{5}{|l|}{ Community weigthed mean of body size } \\
\hline \multirow[t]{3}{*}{ Diversity } & Formi $\downarrow$ & Formi $\downarrow$ & LUI $\downarrow$ & $\mathrm{LUI} \downarrow$ \\
\hline & Inonat $\downarrow$ & & Grazing $\downarrow$ & Mowing $\uparrow$ \\
\hline & Idwcut $\downarrow$ & Idwcut $\downarrow$ & & Fertilization $\uparrow$ \\
\hline \multirow[t]{2}{*}{ Density } & & Idwcut $\downarrow$ & & Grazing $\downarrow$ \\
\hline & & & & Fertilization $\downarrow$ \\
\hline \multirow[t]{2}{*}{ Proportion of sexual individuals } & Formi $\downarrow$ & & & Mowing $\uparrow$ \\
\hline & Inonat $\downarrow$ & & & \\
\hline \multirow[t]{3}{*}{ Proportion of females in sexuals } & & & & LUI $\downarrow$ \\
\hline & & & & Mowing $\uparrow$ \\
\hline & & & & Grazing $\downarrow$ \\
\hline \multirow[t]{3}{*}{ Proportion of gravid females in sexuals } & Inonat $\downarrow$ & Inonat $\downarrow$ & Fertilization $\uparrow$ & Fertilization $\uparrow$ \\
\hline & & Iharv $\downarrow$ & & \\
\hline & & Idwcut $\downarrow$ & & \\
\hline \multirow[t]{2}{*}{ Proportion of gravid females in parthenogens } & & & & Grazing $\downarrow$ \\
\hline & & & Fertilization $\uparrow$ & Mowing $\uparrow$ \\
\hline \multicolumn{5}{|l|}{ Eggs/female in sexuals } \\
\hline Eggs/female in parthenogens & Iharv $\downarrow$ & Iharv $\downarrow$ & & \\
\hline
\end{tabular}

Only signifcant effects are shown. $\downarrow$, negative effect; $\uparrow$, positive effect

Table 7 Proportion of losers and winners species in sexual and parthenogenetic oribatid mite species in forests and grasslands

\begin{tabular}{|c|c|c|c|c|c|c|c|c|}
\hline \multirow[t]{2}{*}{ Forest } & \multicolumn{2}{|l|}{ Formi } & \multicolumn{2}{|c|}{ Idwcut } & \multicolumn{2}{|l|}{ Iharv } & \multicolumn{2}{|l|}{ Inonat } \\
\hline & Loser & Winner & Loser & Winner & Loser & Winner & Loser & Winner \\
\hline Sexual species & 5.9 & 11.8 & 75 & 0 & 4.4 & 1.5 & 7.4 & 10.3 \\
\hline Parthenogenetic species & 0 & 0 & 87.5 & 0 & 4.2 & 4.2 & 0 & 8.3 \\
\hline \multirow[t]{2}{*}{ Grassland } & \multicolumn{2}{|l|}{ LUI } & \multicolumn{2}{|c|}{ Grazing } & \multicolumn{2}{|c|}{ Mowing } & \multicolumn{2}{|c|}{ Fertilization } \\
\hline & Loser & Winner & Loser & Winner & Loser & Winner & Loser & Winner \\
\hline Sexual species & 1.9 & 7.4 & 0 & 0 & 0 & 3.7 & 0 & 1.9 \\
\hline Parthenogenetic species & 0 & 0 & 0 & 6.7 & 0 & 0 & 0 & 0 \\
\hline
\end{tabular}

Formi forest management index, Idwcut proportion of dead wood with saw cuts, Iharv proportion of trees harvested, Inonat proportion of non-native trees, LUI land-use index

sexuals for the land-use index, mowing and fertilization, respectively. Parthenogenetic species did not react as 'losers' to any land-use parameter, but about $7 \%$ 'winners' were found on plots with high grazing intensity. On average, sexual and parthenogenetic oribatid mite species suffered equally from high land-use intensity in forests (23.3 vs. $22.9 \%)$ and 
grasslands (0.5 vs. $0 \%)$. On the other hand, 'winner' species, i.e., those species found on plots with high land-use intensity, were more common among sexual species in both forest (5.9 vs. $3.1 \%)$ and grassland (3.3 vs. $1.7 \%)$ habitats.

\section{Discussion}

\section{Oribatid mite assemblages}

In general, assemblages of oribatid mites in forests were more species-rich, had higher densities and were characterized by species with smaller body than those in grasslands. Furthermore, in both habitats and both regions sexually reproducing species and individuals dominated, except in Schorfheide forests, where the proportion of parthenogenetic individuals was higher than that of sexuals. Our findings are consistent with former studies (e.g., Maraun and Scheu 2000; Cianciolo and Norton 2006; Birkhofer et al. 2012; Erdmann et al. 2012; Wehner et al. 2016).

Although oribatid mites are present in almost all habitats around the world, their abundances vary with habitat and microhabitat conditions (e.g., Maraun and Scheu 2000; Wehner et al. 2016). As an important part of the decomposer system, oribatid mites are most numerous in temperate coniferous and deciduous forests, usually with highest abundances in soils with moder-humus (e.g., Moritz 1965; Scheu and Schulz 1996; Skubala 1999; Maraun and Scheu 2000; Lindo and Visser 2004; Kreibich and Alberti 2006). Former studies on oribatid mites in the framework of the Biodiversity Exploratories correlated their densities with forest type and age showing highest numbers in coniferous and lowest numbers in natural beech stands (Erdmann et al. 2012; Bluhm et al. 2016). Also in several grasslands, oribatid mites are among the most diverse and abundant arthropod groups (Behan-Pelletier and Kanashiro 2010).

Theory predicts that the distribution of the mode of reproduction in oribatid mites depends on the availability of resources in a certain habitat (Scheu and Drossel 2007). Higher percentages of parthenogenesis can be found in coniferous forests as compared to beech stands or acidic forests (Maraun et al. 2012, 2019; Bluhm et al. 2016) and even microhabitats within forests differ in the percentage of parthenogenetic inhabitants (Wehner et al. 2018). Although also in oribatid mites the majority of species reproduce by sexuality, the comparably high amount of parthenogenesis and the stable coexistence of sexually and parthenogenetically reproducing species remain remarkable.

Sex ratios within oribatid mite species were relatively constant among habitat and regions and seem to be species specific. In sexuals, for example, O. calcarata and Chamobates cuspidatus are usually characterised by relatively low percentages of females (below 50\%), whereas the sex ratios of larger species such as Eupelops sp. and Euzetes sp. are highly female biased (Wehner et al. 2016, 2018; but see Luxton 1981). A femalebiased sex-ratio may reduce the so-called twofold costs of sex which arise by the production of males: for example, in sexually reproducing onion thrips (Thrips tabaci) the population growth rate increases by reducing the frequency of male offspring and adjusts to the growth rate of parthenogenetic strains (Kobayashi and Hasegawa 2016). How far these findings can be transferred to coexisting sexual and parthenogenetic oribatid mite species needs further investigation of population dynamics.

In addition to their high percentages in oribatid mite assemblages, sexual species showed a higher proportion of gravidity and had $1.6 \times$ more eggs than parthenogens, which 
agrees with previous studies (Domes et al. 2007; Wehner et al. 2014). A higher gravidity rate and more eggs per gravid female may also reduce the twofold costs of sex by further adjusting the number of female progeny to that of parthenogens.

In parthenogenetically reproducing species of Enarthronota, Mixonomata and Nothrina, males were completely absent, but in O. nova and Tectocepheus spp. spanandric males were found. These males - which are assumed to be evolutionary artefacts (Taberly 1988) — are regularly found irrespective of habitat or season (Fujikawa 1988a, b; Wehner et al. 2014, 2016, 2018). If and how much these males contribute to the genetic diversity of parthenogenetic species is still unknown and needs further investigation.

\section{Influence of land-use intensity}

Whereas effects of different land-use intensity on diversity and abundance of oribatid mite communities in forests were almost all negative, the strength and direction of effects in grasslands depended on region. On the species level, we found the same number of 'losers' in sexual and parthenogenetic species at high land-use intensities in both habitats, but 'winner' species were more common among sexuals.

In forests, land-use management can have strong local modulating effects influencing soil nutrient quality, water availability, the vegetation type of the shrub layer and tree composition (Zaitsev et al. 2013). In temperate forest soils, oribatid mites are an important component of the decomposer system, somehow buffering mechanisms against strong environmental changes and showing a multifaceted reaction to long-lasting disturbances (Zaitsev et al. 2002). The reaction of the soil community and especially oribatid mites to disturbance depends on the kind of land use (Marshall 2000; Birkhofer et al. 2012, 2017). Clear-cutting can reduce oribatid mite abundance up to $90 \%$ and changes oribatid mite community composition due to soil compaction and a following reduction and restructuring of the microbial community; partial-cut, stem-only harvesting or selective timber harvesting is usually less detrimental to forest floor microarthropods (Hope 2001; Battigelli et al. 2004; Bird et al. 2004; Lindo and Visser 2004). Furthermore, the removal of cut timber reduces important habitats (Déchêne and Buddle 2009). As several oribatid mite species are obligate members of the intra-log community (Siira-Pietikäinen et al. 2018; Skubala and Duras 2008), dead wood is important for diverse and unique oribatid mite assemblages (Déchêne and Buddle 2009).

In our study, the presence of unnatural dead wood-showing saw cuts from timber harvesting - had a negative impact on a high proportion of oribatid mite species in the litter, irrespective of their mode of reproduction. The presence of unnatural dead wood does not mean that the total amount of dead wood at a specific site is enhanced; it rather describes the enhanced proportion of dead wood with saw cuts relative to the total amount of dead wood. An explanation for the negative effect of unnatural dead wood on oribatid mite assemblages would require further experimental studies adding different kinds of dead wood, i.e., natural or artificial. For now, we assume that dead wood specialists may migrate from the litter to the available dead wood habitats, thereby lowering oribatid mite diversity and abundance in litter. However, this does not explain why natural dead wood would not have the same effect. It is also plausible that wood harvesting changed ecological conditions by, e.g., soil compaction due to timber removal, drought due to soil exposure after clear-cutting and other changes of the microclimate, and oribatid mite species may react by decreasing abundance. Probably the proportion of dead wood with saw cuts is the best 
indicator for overall harvesting disturbances for soil animals, reflecting all environmental changes mentioned before.

Furthermore, effects on animal communities are often difficult to separate (Minor et al. 2004; Wehner et al. 2018). A further parameter that can have an impact on soil animals by influencing soil structure, microclimate, water regime, microflora, and habitat diversity is the aboveground vegetation (Berg and Powluk 1984; Birkhofer et al. 2012). Birkhofer et al. (2012) showed that anthropogenic disturbances by different land-use types alter soil properties and strongly influence soil biota. In their study, oribatid mites were more abundant at sites with low $\mathrm{pH}$ and nitrate concentration.

In grasslands, land use often causes extremely perturbed soil by physical and/or chemical means. Fertilization or monocultures in grasslands lead to unnatural plant communities and pesticides and desiccation destroy habitat structure (Birkhofer et al. 2012; Lehmitz 2014). The alteration of physical soil properties reduces oribatid mite richness and density and alters the community structure. Furthermore, the usage of synthetic fertilizers has been shown to negatively affect abundance and diversity of oribatid mite communities by enhancing the nitrate concentration in soil (Birkhofer et al. 2012) which agrees to this study. Soil compaction due to livestock grazing and mowing can also decrease the abundance of small species and those intolerant to drought (Siepel 1996; Ivan 2009). In our study, grasslands showed far fewer 'loser' species than did forests, and up to $7.4 \%$ were 'winners' in sexuals. This indicates that grassland communities consist of more tolerant species that can cope with the greater amount of natural and human-introduced uncertainty in their habitat. Furthermore, oribatid mite species may profit from a stable soil microflora that gets continuous input of organic matter from litter and roots all year round (VreekenBuijs et al. 1998).

\section{Conclusion}

In conclusion, not all land-use parameters showed negative effects on oribatid mite communities; in grasslands, also positive effects were observed. Biodiversity was generally more strongly affected than abundance. On the species level, sexual and parthenogenetic species suffered about equally from high land-use intensity, showing approximately equal proportions of 'loser' species. While most parthenogenetic species produced all-female offspring that may quickly recolonize disturbed habitats, sexual species hold up with female biased sex ratios, a higher percentage of gravidity and more eggs per gravid female which may enable those species to cope with land-use disturbances and to be 'winners' at high land-use intensities.

Supplementary information The online version of this article (https://doi.org/10.1007/s10493-020-00586 -z) contains supplementary material, which is available to authorized users.

Acknowledgements We thank the managers of the three Exploratories, Kirsten Reichel-Jung, Iris Steitz, Sandra Weithmann, Juliane Vogt, Miriam Teuscher and all former managers for their work in maintaining the plot and project infrastructure, Christiane Fischer for giving support through the central office, Andreas Ostrowski for managing the central database, and Markus Fischer, Eduard Linsenmair, Dominik Hessenmöller, Daniel Prati, Ingo Schöning, François Buscot, Ernst-Detlef Schulze and the late Elisabeth Kalko for their role in setting up the Biodiversity Exploratories project. Many thanks to all research assistants: Kevin Frank, Wiebke Kämper, Jessica Schneider, Andrea Hilpert, Matteo Trevisan, Matthias Brandt, Tewannakit 
Mermagen, Kathrin Ziegler, Annika Keil, Andreas Kerner, and Katja Gruschwitz. We also thank three reviewers for their substantial contributions.

Author contributions NB and MH designed the study on oribatid mites; NKS analyzed the data; RAN supported species identification; RS collected specimens; KW did the fieldwork, identified species, analyzed the data and wrote the manuscript. All authors significantly commented on earlier drafts of the manuscript.

Funding Open Access funding enabled and organized by Projekt DEAL. The work has partly been funded by the DFG Priority Program 1374 "Infrastructure-Biodiversity-Exploratories" (DFG BL860/8-3). Fieldwork permits were issued by the responsible state environmental offices of Baden-Württemberg, Thüringen, and Brandenburg (according to $\S 72$ BbgNatSchG). We acknowledge the Open Access Publishing Fund of Technische Universität Darmstadt.

Availability of data Data are deposited at the Bexis database ID 26446 and openly available under https:// doi.org/10.25829/bexis.26446-3 or from the corresponding author upon request.

Code availability For statistical analyses, R version and RStudio version 3.5.2 were used. R scripts can be obtained from the corresponding author upon request.

\section{Compliance with ethical standards}

Conflict of interest The authors declare no conflict of interests.

Ethical approval The manuscript is not under consideration for publication in another journal and all authors have approved its submission for publication as a research article. All persons entitled to authorship have been so named. All authors have seen and agreed to the submitted version of the manuscript.

Open Access This article is licensed under a Creative Commons Attribution 4.0 International License, which permits use, sharing, adaptation, distribution and reproduction in any medium or format, as long as you give appropriate credit to the original author(s) and the source, provide a link to the Creative Commons licence, and indicate if changes were made. The images or other third party material in this article are included in the article's Creative Commons licence, unless indicated otherwise in a credit line to the material. If material is not included in the article's Creative Commons licence and your intended use is not permitted by statutory regulation or exceeds the permitted use, you will need to obtain permission directly from the copyright holder. To view a copy of this licence, visit http://creativecommons.org/licenses/by/4.0/.

\section{References}

Allan E, Manning P, Alt F et al (2015) Land use intensification alters ecosystem multifunctionality via loss of biodiversity and changes to functional composition. Ecol Lett 18:834-843

Attwood SJ, Maron M, House ARN, Zammit C (2008) Do arthropod assemblages display globally consistent responses to intensified agricultural land use and management? Glob Ecol Biogeogr 17:585-599

Battigelli JP, Spence JR, Langor DW, Berch SM (2004) Short-term impact of forest soil compaction and organic matter removal on soil mesofauna density and oribatid mite diversity. Can J For Res 34:1136-1149

Behan-Pelletier VM (1999) Oribatid mite biodiversity in agroecosystems: role for bioindication. Agric Ecosyst Environ 74:41-423

Behan-Pelletier VM, Kanashiro D (2010) Acari in grassland soils of Canada. In: Shorthouse JD, Floate KD (eds) Arthropods of Canadian grasslands (volume 1): ecology and interactions in grassland habitats. Biological Survey of Canada, Ottawa, pp 137-166

Bell G (1982) The masterpiece of nature. The Evolution and Genetics of Sexuality. University of California Press, California

Berg NW, Pawluk S (1984) Soil mesofaune studies under different vegetative regimes in Noth Central Alberta. Can J Soil Sci 64:209-223 
Bird SB, Coulson RN, Fisher RF (2004) Changes in soil and litter arthropod abundance following tree harvesting and site preparation in a loblolly pine (Pinus taeda L.) plantation. For Ecol Manag 202:195-208

Birkhofer K, Bezemer TM, Bloem J et al (2008) Long-term organic farming fosters below and aboveground biota: implications for soil quality, biological control and productivity. Soil Biol Biochem 40:2297-2308

Birkhofer K, Schöning I, Alt F et al (2012) General relationships between abiotic soil properties and soil biota across spatial scales and different land-use types. PLoS ONE 7(8):e43292. https://doi. org/10.1371/journal.pone.0043292

Birkhofer K, Dietrich C, John K, Schorpp Q, Zaitsev AS, Wolters V (2016) Regional conditions and landuse alter the potential contribution of soil arthropods to ecosystem services in grasslands. Front Ecol Evol 3:150. https://doi.org/10.3389/fevo.2015.00150

Birkhofer K, Gossner MM, Diekötter T et al (2017) Land-use type and intensity differentially filter traits in above- and below-ground arthropod communities. J Anim Ecol 86:511-520

Bluhm C, Scheu S, Maraun M (2016) Temporal fluctuations in oribatid mites indicate that density-independent factors favour parthenogenetic reproduction. Exp Appl Acarol 68:387-407

Blüthgen N, Dormann CF, Prati D et al (2012) A quantitative index of land-use intensity in grasslands: integrating mowing, grazing and fertilization. Basic Appl Ecol 13:207-220

Chisté M, Mody K, Gossner MM, Simons NK, Köhler G, Weisser WW, Blüthgen N (2016) Losers, winners, and opportunists: how grassland land-use intensity affects orthopteran communities. Ecosphere 7(11): 01545

Chisté MN, Mody K, Kunz G, Gunczy J, Blüthgen N (2018) Intensive land use drives small-scale homogenization of plant- and leafhopper communities and promotes generalists. Oecologia 186:529-540

Cianciolo JM, Norton RA (2006) The ecological distribution of reproductive mode in oribatid mites, as related to biological complexity. Exp Appl Acarol 40:1-25

Culman SW, Young-Mathews A, Hollander AD, Ferris H, Sánchez-Moreno S, O`Green AT, Jackson LE (2010) Biodiversity is associated with indicators of soil ecosystem functions over a landscape gradient of agricultural intensification. Landscape Ecol 25:1333-1348

Déchêne AD, Buddle CM (2009) Decomposing logs increase oribatid mite assemblage diversity in mixedwood boreal forests. Biodivers Conserv 19:237-256

Domes K, Scheu S, Maraun M (2007) Resources and sex: soil re-colonization by sexual and parthenogenetic oribatid mites. Pedobiologia 51:1-11

Ehnes RB, Pollierer MM, Erdmann G, Klarner B, Eitzinger B, Digel C, Ott D, Maraun M, Scheu S, Brose U (2014) Lack of energetic equivalence in forest soil invertebrates. Ecology 95:527-537

Erdmann G, Scheu S, Maraun M (2012) Regional factors rather than forest type drive the community structure of soil living oribatid mites (Acari, Oribatida). Exp Appl Acarol 57:157-169

Fischer M, Bossdorf O, Gockel S et al (2010) Implementing large-scale and long-term functional biodiversity research: the Biodiversity Exploratories. Basic Appl Ecol. 11:473-485

Fujikawa T (1988a) Biology of Tectocepheus velatus (Michael) and T. cuspidentatus Knülle. Acarologia 29:307-315

Fujikawa T (1988b) Biological features of Oppiella nova (Oudemans) in a nature farming field. Edaphologia 38:1-10

Gossner MM, Lewinsohn T, Kahl T et al (2016) Land-use intensification causes multitrophic homogenisation of grassland communities. Nature 540:266-269. https://doi.org/10.1038/nature20575

Hope G (2001) The soil ecosystem of an ESSF forest and its response to a range of harvesting disturbances. Extension Note 53. B. C. Ministry of Forests Research Program, Victoria, B. C. Available from http:// www.for.gov.bc.ac/hfd/pubs/Docs/En/En53.htm

Ivan O (2009) Diversity and distribution of the oribatid mites (Acari, Oribatida) in some grassland ecosystems from the lower section of the prut meadow (Romania). Agranomie 52:359-364

Jost L (2006) Entropy and diversity. Oikos 113:363-375. https://doi.org/10.1111/j.2006.0030-1299.14714.x

Kahl T, Bauhus J (2014) An index of forest management intensity based on assessment of harvested tree volume, tree species composition and dead wood origin. Nat Conserv 7:15-27

Kempson D, Llyod M, Ghelardi R (1963) A new extractor for woodland litter. Pedobiologia 3:1-21

Klarner B, Ehnes RB, Erdmann G, Eitzinger B, Pollierer MM, Maraun M, Scheu S (2014) Trophic shift of soil animal species with forest type as indicated by stable isotope analysis. Oikos 123:1173-1181

Kobayashi K, Hasegawa E (2016) A female-biased sex ratio reduces the twofold cost of sex. Sci Rep $6: 23982$

Kreibich E, Alberti G (2006) Reactions of oribatid mites (Acari: Oribatida) to changed forestry methods in the lowlands of northeastern Germany. Fragm Faun 49:133-151 
Lehmitz R (2014) The oribatid mite community of a German peatland in 1987 and 2012 —effects of anthropogenic desiccation and afforestation. Soil Org 86:131-145

Lehmitz L, Russell D, Hohberg K, Christian A, Xylander WER (2012) Active dispersal of oribatid mites into young soil. Appl Soil Ecol 55:10-19

Lehtonen J, Jennions MD, Kokko H (2012) The many costs of sex. Trends Ecol Evol 27:172-178

Liiri M, Häsä M, Haimi J, Setälä H (2012) History of land-use intensity can modify the relationship between functional complexity of the soil fauna and soil ecosystem services-a microcosm study. Appl Soil Ecol 55:53-61

Lindo Z, Visser S (2004) Forest floor microarthropod abundance and oribatid mite (Acari: Oribatida) composition following partial and clear-cut harvesting in the mixedwood boreal forest. Can J For Res 34:998-1006

Luxton M (1981) Studies on the oribatid mites of a Danish beech wood soil. IV Developmental biology. Pedobiologia 21:312-340

Mangels J, Fiedler K, Schneider FD, Blüthgen N (2017) Diversity and trait composition of moths respond to land-use intensification in grasslands: generalists replace specialists. Biodivers Conserv 26:3385-3405

Maraun M, Scheu S (2000) The structure of oribatid mite communities (Acari, Oribatida): patterns, mechanisms and implications for future research. Ecography 3:374-383

Maraun M, Norton RA, Ehnes RB, Scheu S, Erdmann G (2012) Positive correlation between density and parthenogenetic reproduction in oribatid mites (Acari) supports the structured resource theory of sexual reproduction. Evol Ecol Res 14:311-323

Maraun M, Caruso T, Hense J et al (2019) Parthenogenetic vs. sexual reproduction in oribatid mite communities. Ecol Evol 9:7324-7332

Marshall VG (2000) Impacts of forest harvesting on biological processes in northern forest soils. For Ecol Manag 133:43-60

Maynard Smith J (1978) The evolution of sex. Cambridge University Press, Cambridge

Minor M, Volk TA, Norton RA (2004) Effects of site preparation techniques on communities of soil mites (Acari: Oribatida, Acari: Gamasida) under short-rotation forestry plantings in New York, USA. Appl Soil Ecol 25:181-192

Moritz M (1965) Untersuchungen über den Einflus von Kahlschlagmaßnahmen auf die Zusammensetzung von Hornmilbengemeinschaften (Acari: Oribatai) norddeutscher Laub- und Kiefernmischwälder. Pedobiologia 5:65-101

Newbold T, Hudson LN, Hill SLL et al (2005) Global effects of land use on local terrestrial biodiversity. Nature 520:45-50

Norton RA (1990) Acarina: Oribatida. In: Dindal D (ed) Soil biology guide. Wiley, New York, pp 779-803

Norton RA, Palmer SC (1991) The distribution, mechanisms, and evolutionary significance of parthenogenesis in oribatid mites. In: Schuster R, Murphy PW (eds) The Acari: reproduction, development and life-history strategies. Chapman \& Hall, London, pp 107-136

Oksanen J, Blanchet FG, Friendly M et al. (2019). vegan: community Ecology Package. R package version 2.5-6. https://CRAN.R-project.org/package=vegan

Penone C, Allan E, Soliveres S et al (2019) Specialisation and diversity of multiple trophic groups are promoted by different forest features. Ecol Lett 22:170-180

R Core Team (2018) R: a language and environment for statistical computing. Vienna: R Foundation for Statistical Computing. Available at https://www.R-project.org/

Schatz H, Behan-Pelletier V (2008) Global diversity of oribatids (Oribatida: Acari: Arachnida). Hydrobiologia 595:323-328

Schatz H, Behan-Pelletier VM, OConnor BM, Norton RA (2011) Suborder Oribatida van der Hammen, 1968. In: Zhang Z-Q (ed) Animal biodiversity: an outline of higher level classification and survey of taxonomic richness. Zootaxa 3148:141-148

Scheu S, Drossel B (2007) Sexual reproduction prevails in a world of structured resources in short supply. Proc R Soc B 274:1225-1231

Scheu S, Schulz E (1996) Secondary succession, soil formation and development of a diverse community of oribatids and saprophagous soil macro-invertebrates. Biodivers Conserv 5:235-250

Seastedt TR (1984) The role of microarthropods in decomposition and mineralization processes. Annu Rev Entomol 29:25-46

Seastedt TR, Crossley DA Jr (1981) Microarthropod response following cable logging and clear-cutting in the southern Appalachians. Ecology 62:126-135

Siepel H (1996) The importance of unpredictable and short-term environmental extremes for biodiversity in oribatid mites. Biodiv Letters 3:26-34

Siira-Pietikäinen A, Penttinen R, Huhta V (2018) Oribatid mites (Acari: Oribatida) in boreal forest floor and decaying wood. Pedo 52:11-118 
Skubala P (1999) Comparison of adult oribatid mites (Acari, Oribatida) from three mountain forests in Poland: I. Abundance, biomass and species richness. In: Bruin J, van der Geest LPS, Sabelis MW (eds) Ecology and evolution of Acari. Kluwer Academic, Dordrecht, pp 547-555

Skubala P, Duras M (2008) Do decaying logs represent habitat islands? Oribatid mite communities in dead wood. Anal Zool 58:453-466

Taberly G (1988) Recherches sur la parthénogenèse thélythoque de deux espèces d'acariens oribatides: Trhypochthonius tectorum (Berlese) et Platynothrus peltifer (Koch). IV Observations sur les mâles ataviques. Acarologia 29:95-107

Vreeken-Buijs MJ, Hassink J, Brussaard L (1998) Relationship of soil microarthropod biomass with organic matter and pore size distribution in soils under different land use. Soil Biol Biochem 30:97-106

Wallwork JA (1983) Oribatids in forest ecosystems. Annu Rev Entomol 28:109-130

Wehner K, Scheu S, Maraun M (2014) Resource availability as driving factor of the reproductive mode in soil microarthropods (Acari, Oribatida). PLoS ONE 9(8):e104243. https://doi.org/10.1371/journ al.pone.0104243

Wehner K, Norton RA, Blüthgen N, Heethoff M (2016) Specialization of oribatid mites to forest microhabitats- the enigmatic role of litter. Ecosphere 7(3):e01336

Wehner K, Heethoff M, Brückner A (2018) Sex ratios of oribatid mite assemblages differ among microhabitats. Soil Org 90:13-21

Weigmann G (2006) Hornmilben (Oribatida). In: Dahl (ed) Tierwelt Deutschlands 76. Goecke and Evers, Keltern

Wolters V (2001) Biodiversity of soil animals and its function. Eur J Soil Biol 37:221-227

Zaitsev AS, Chauvat M, Pflug A, Wolters V (2002) Oribatid mite diversity and community dynamics in a spruce chronosequence. Soil Biol Biochem 34:1919-1927

Zaitsev AS, van Straalen NM, Berg MP (2013) Landscape geological age explains large scale spatial trends in oribatid mite diversity. Landscape Ecol 28:285-296

Publisher's Note Springer Nature remains neutral with regard to jurisdictional claims in published maps and institutional affiliations.

\section{Affiliations}

\section{Katja Wehner ${ }^{1}$ (D) Romina Schuster ${ }^{2} \cdot$ Nadja K. Simons ${ }^{1} \cdot$ Roy A. Norton ${ }^{3}$. Nico Blüthgen ${ }^{1} \cdot$ Michael Heethoff $^{1}$}

1 Ecological Networks, Technische Universität Darmstadt, Schnittspahnstraße 3, 64287 Darmstadt, Germany

2 Institut für Bodenkunde und Standortlehre, Universität Hohenheim, Emil-Wolff-Straße 27, 70599 Stuttgart, Germany

3 College of Environmental Science and Forestry, State University of New York, 1 Forestry 16 Drive, Syracuse, NY 13210, USA 